\title{
An Assessment Study on the Prevalence and Causes of Early Marriage and its Associated Problems on Socio-Economic and Health of Women in Gozamine Woreda East Gojjame Zone Amhara Region
}

Zelalem Desalegne Basazinewu ${ }^{1}$

${ }^{\prime}$ Haramaya University CSSH, Ethiopia Email: zelalem.love@yahoo.com

Licensed:

This work is licensed under a Creative Commons Attribution 4.0 License.

Keywords:

Consaguinea kinship

Early marriage

Tradition

Females

Virginity.

\begin{abstract}
Early marriage has all rounded problem on women and girls in the world in general and in developing countries in particular. It results on the health, and socio economic aspects of romen; mistreatment, marginalization and deny basic human rights of women. Early marriage also limits many women's mobility, self-esteem, ability to seek profitable employment, household decision making power, and/or increase the vulnerability to violence. Each of these factors has a potent effect on a woman's ability to access healthcare, compromising not only her own health but that of her children, and not to be competent in economic and social affairs. This paper aimed to examine and investigate the prevalence of early marriage in the study area (gozamine woreda); identify the causal factors of early marriage in the study area, and examine its associated problems which put its impact on the health and socio-economic condition of women. After the list of kebeles obtained from the woreda administration office three kebeles were selected for the sake of this study through area cluster sampling method. Consequently a total of 350 ever married women who were under the age 15-50 years were included in the study selected through random sampling method. The quantitative data obtained from the questionnaire was analyzed through SPSS 19. Whereas the qualitative data was collected through FGDs (three FGDs with 30 members totally) and six interviewees were interviewed for the in-depth interview. In gozamin woreda people wed children early due to different reasons. Among the identified factors keeping the tradition, keeping girls' virginity, premarital sex and pregnancy, parents interest to create affinal relatives, economic, and lack of knowledge are the main causal factores of early marriage in the area. The main consequences of early marriage identified in the study area are girls school dropout, marriage instability, early pregnancy, maternal mortality, fistula and HIV/AIDS infection, and increased number of children. In general early marriage in the study area is remarkably decreasing.
\end{abstract}

1. Introduction

1.1. Background of the Study

The term Early Marriage is used to refer to both formal marriages and informal unions in which a girl lives with a partner as if married before the age of 18 (UNICEF, 2005). According to International Planned Parenthood Foundation (2006) early marriage, also known as Child marriage, is defined as any marriage carried out below the age of 18 years, before the girl is physically, physiologically, and psychologically ready to shoulder the responsibilities of marriage and childbearing. Child marriage, on the other hand, involves either one or both spouses being children and may take place with or without formal registration, and under civil, religious or customary laws.

Marriage is a social institution that unites people in a special form of mutual dependence for the purpose of founding and maintaining a family. As a social practice entered into a public act, religious or traditional ceremony, it reflects the purposes, characters, and customs of the society in which it is found. Many societies have norms that limit the age of young girls to enter into marriage, but in some cases the age limit does not take their physiological readiness for childbearing into consideration. Marriage often takes place at ages much earlier than the legally ratified minimum age. Early marriage is the marriage of children and adolescents below the age of 18 (UNFPA, 2006). 
The practice of early marriage is most common in sub-Saharan Africa and South Asia. In specific parts of West Africa, East Africa and South Asia, marriage before puberty is not unusual. In North Africa, the Middle East, and other parts of Asia, marriage shortly after puberty is common among those leading traditional lifestyles. Marriages of female adolescents between sixteen and eighteen years of age are also common in parts of Latin America and Eastern Europe. Among those marrying early, some are forced into this union, others are simply too young to make an informed decision. Because the child does not have the opportunity to exercise her right to choose, early marriages are also referred to as forced marriages. In its most extreme form, forced marriages are the result of abductions (UNICEF, 2005).

A study conducted by the Demographic and Health Survey, 2005 show that substantial proportion of women in developing countries continue to marry at the age of adolescence. Overall, $20-50 \%$ of women marred or entered in to a union by the age of 18 , and $40-70 \%$ does so when they are 20. Early marriage is most prevalent in Sub-Saharan Africa and in South Asia and least common in North Africa, the Middle East and Southeast Asia. Women aged 20-24 are less likely to get married by the age of 20 than are women aged 40-44; the differential is at least $10 \%$ in most countries and reaches $30-40 \%$ in some countries. Education level plays a paramount role; a woman who has attended secondary school is considerably less likely to marry during adolescence and in countries with a higher proportion of women with a secondary education, the proportion of women who marry as adolescence is lower (DHS, 2005).

One in seven girls in the developing world marries before 15 (Population Council, 2010). Nearly half of the 331 million girls in developing countries are expected to marry by the age of 20 . If this rate goes on likewise, 100 million more girls or 25,000 more girls every day will become child brides in the next decade. The U.S. government and international community increasingly are concerned about the prevalence of child marriage and its toll on girls in developing countries (Save the Children, 2004). In response to congressional interest, the U.S. Agency for International Development (USAID) sought to learn more about the extent and effectiveness of current development efforts to reduce the prevalence of child marriage.

The Inter-agency Gender Working Group (IGWG) at USAID a network of non- governmental organizations and cooperating agencies working with USAID to promote gender equity in population, health and nutrition programs found that although child marriage is closely related to other development efforts, the issue is not being addressed systematically within USAID programs. USAID country mission and cooperating agency staff could describe only a few activities that addressed child marriage either directly or indirectly in their programs. Furthermore, these activities are confined to only a few countries and implementing partners. Field staff also acknowledged that child marriage undermines other development efforts, and a number of staff provided thoughtful and strategic ideas for addressing child marriage through existing efforts (USAID, 2008).

According to IGWG Current literatures across the world concerning early marriage focused primarily on examining the prevalence, consequences and reasons reported by parents for early marriage. Much less is known about the actual risk factors for child marriage, what may serve to protect girls from marrying too young, and how most effectively to change the social acceptance of early marriage. Identifying these factors would bolster efforts to design targeted interventions that prevent child marriage. A better understanding of risk and protective factors and social norms could also inform program designs to mitigate these risks and strengthen protective factors or create them where they do not exist (ibid).

In Ethiopia in general and in the Amhara region in particular, females are highly disadvantaged and less privileged as the tradition favors male domination in the society. Men are the only decision makers in the family in terms of money, wealth, property etc. Women do not have a say even to limit the number of children in the family. In the region, there is high prevalence of harmful traditional practices like Female Genital Mutilation, early marriage and illegitimate marriage that jeopardize the reproductive health situation of women. Most children (81.1\%) in the region undergo FGM and $82 \%$ of girls are married before the age of 18 (Ethiopia Demographic \& Health Survey, 2005).

The findings of some surveys indicated that the mean age for first marriage is 12.8 years for girls. It is also argued that $98 \%$ of the marriage agreement is done by the will of parents. As a result, $74 \%$ of girls bear the burden of marriage before they reach 15 years old. Hence, early marriage is by far the most serious HTP in the region in general and in rural areas in particular. It causes complicated pregnancies that may lead to mortality and morbidity; It can result in obstetric fistulas; it causes school dropout, it limits married girls autonomy and decision making ability. In general it deprives them of all their rights (EDHS, 2005).

Moreover, the people in the Amhara region in general and the people in the rural parts of the region in particular are deprived of the basic reproductive health information and services. The poor reproductive health situation of the region is evidenced by low health coverage, high infant mortality rate (94 per 1000 births), high maternal mortality (673 deaths per 100,000 live births), high fertility rate (5.1 children per women), and high unmet need for family planning services (30\%) with a very low contraceptive prevalence rate $(16 \%)$, increasing number of reported unsafe abortion and high adult HIV prevalence rate $4.5 \%$ which occurs due to mothers illiteracy as a result of early marriage (EDHS, 2005). 


\subsection{Statement of the Problem}

The National Committee for Traditional Practices in Ethiopia identified 120 Harmful Traditional Practices (HTPs), including early and forced marriage. Harmful Traditional Practices cause a serious social, economic, and political destruction. These traditional beliefs and practices have caused violence and discrimination on children, girls and women. But the range and magnitude of the HT beliefs and practices is different across age and sex. Owing to the socially constructed and assigned roles and responsibilities, girls and women are the first and prime harmed groups (National Committee on Traditional Practices of Ethiopia, 2003; Pathfinder International/Ethiopia, 2007). Likewise in Gozamin Woreda, early marriage was and is practiced for many years due to traditional and religious covers. Early marriage is widely proliferated and is causing serious societal, economical and health problems.

According to Path Finder international Ethiopia, 2006, 15\% of ever-married women in Amhara married before the age of 12 . The mean age at first marriage was 14.5 years, and about $44 \%$ of urban and $53 \%$ of rural ever-married women were first married between 12 and 15 years. Only $16.2 \%$ of rural women and $26.6 \%$ of urban women married at the age of 18 or older. More than one third of the ever-married women had married at least twice, and $14 \%$ of these women had married three or more times. The majority of women did not involve in any economic activities. Literacy among females with an age range of 12-49 in the region is less than $40 \%$. Only 15 percent were educated beyond the primary level (Pathfinderr International/Ethiopia, 2006).

Nearly three-fourths of the ever-married women had married men older than themselves, and the age difference was 10 years or more for half of the women married to older men across the region. These results do not show variation by place of residence. More than half of the married women in the region were pressurized to marry, largely by their parents. This was more common in rural than urban areas (ibid).

According to United Nations Educational (2002a) a study on married adolescents aged 15-49 revealed that early marriage is affecting girls more but, it is also a problem of boys too. In Ethiopia $6.2 \%$ of boys and $30.9 \%$ of girls, Egypt $2.8 \%$ of boys and $15 \%$ of girls, Malawi $5.75 \%$ of boys and $43.65 \%$ of girls, Niger $4.2 \%$ of boys and $61.9 \%$ of girls, Bangladesh $5 \%$ of boys and $51.3 \%$ of girls, India $9.5 \%$ of boys and $35.7 \%$ of girls, France $2.9 \%$ of boys and $0.8 \%$ of girls, Bulgaria $3.1 \%$ of boys $16.5 \%$ of girls, and Cambodia $7.7 \%$ of boys and $20 \%$ of girls marry before the age of 18 . This data shows that African and Asian countries are high in early marriage, whereas developed countries are low in early marriage. Ethiopia is remarkably third in the world in boys' early marriage The prevalence of early marriage is different across the world. The problem is affecting millions of boys and girls lives in varying degree from country to country and from continent to continent, but is more problematic in sub-Saharan African and Asian countries (Singh \& Samara, 1996).

Early Marriage-though Gozamine Woreda is near to the zonal city Debre Markos, early marriage is a common practice in rural areas. Many girls marry before the normal marriage age $/ 18 /$. This decreases young girls' exposure to education, employment opportunity, and increase young women's risk to HIV/AIDS infection. This is attributed to lack of awareness about the virus, due to their tinder age, and lack of power in the family. In the woreda, many girls are exposed to early marriage which results in girls' drop out from school, forced sex which further results in early pregnancy having disastrous consequences on her health. Hence, marriage arranged by parents which is not consensual contributes to domestic violence and subsequent vulnerability. Eventually, this perpetuates unrelenting cycle of gender inequality (Culture and Tourism Office, 2004).

Amhara region is one of the regions where early marriage is highly prevalent. Different researches show that early marriage is practiced with a varying degree of prevalence throughout the region. No matter how different the prevalence in different regions, women in East and West Gojjam and North and South Gondar take the lion's share (Pathfinderr International/Ethiopia, 2006). However, there are no previous findings that indicate the prevalence, causes and consequence of early marriage in Gozamine woreda. Therefore, this study helps to come up with up-to date data about the prevalence, causes and associated problems /consequences/ it may bring about on women.

\subsection{Research Questions}

This study tries to answer the following research questions:

1. What is the magnitude of early marriage in the study area?

2. What are the causes for its prevalence?

3. At what age range does early marriage appear sever?

4. How does it affect women's health and their socio-economic status?

\subsection{General Objective}

The general objective of this research study is to assess the prevalence, identify the factors and to investigate the impacts of early marriage on socio-economic and health condition of women in the study area. 


\subsection{Specific Objective}

1. To identify the prevalence of early marriage in the study area

2. To investigate the impacts of early marriage on women socio-economic, health condition, access to and control over resource in the study area;

3. To explore the root causes and locally contributing factors for its long existence and prevalence;

4. To investigate the nature, magnitude and context of early marriage in the study area; and

5. To suggest possible way outs and solutions with appropriate strategies.

\subsection{Significance of the Study}

This study will help Women, Children, and Youth Office and other stakeholders to know the extent of early marriage in the woreda. It can be a candle light for the office and helps to design a way out, serves as a training manual.

-It could function as a reference and baseline for other researchers to conduct further study on early marriage. -It serves as an alarm call to the community in which women are discriminated and subordinated due to early marriage.

-It also informs the culture and tourism office to work seriously on HTP like early marriage.

-It will also be important for legal institutions to get a good deal of information on it and take actions on it.

-This research serves as a pull factor for GOs, NGOs, and Charitable organizations to launch their program on the study area /Gozamine/ by showing the prevalence of early marriage.

-Different GOs, NGOs, and Charitable organizations may use it as a training material /manual for.

\subsection{Scope of the Study}

Early marriage is a serious problem in Amhara region mainly East and West Gojjam. Gozamine Woreda is amongst those areas where harmful practices are practiced. Owing to this, different scholars have conducted research concerning traditional practices that are creating social, economic, physical, psychological and political problems on the society. To this end, this study has focused only on the assessment of the prevalence, causes and impacts of early marriage on the social-economic and health condition of married women aged from 15-50. This study is conducted in Gozamine Woreda East Gojjam Administrative Zone Amhara Region on three selected kebeles through area cluster sampling technique.

\subsection{Limitation of the Study}

The major limitations in undertaking this study were unavailability of the necessary documents which could serve as an input for the study on the prevalence, causes of early marriage and its associated problems on socio-economic and health condition of women in the study area. Though there are different researches at the national and international level, there are no researches and necessary documents in the study area on early marriage even in the office of women, children and youth.

The translation of primary and secondary sources of data was too difficult, which were documented and collected through the local Amharic language. Financial constraint was the other draw back encountered while conducting this research. As the researcher is self-sponsored and has no any financial support from any external body, it was difficult to give substantive pays for data collectors and FGD moderators.

\section{Literature Review}

\subsection{The Prevalence of Early Marriage Gender Inequality}

Gender inequality persists in most societies despite global statements of commitment to empower women and improve gender equality. In many societies worldwide power structures are still overwhelmingly maledominated or patriarchal. Under such conditions, the marriage of girls is perceived as a necessary way of reinforcing existing norms. It ensures that girls and women accept their domestic roles and have a limited role within the wider society. This clearly results in women's total dependency on men. Therefore, any government making genuine efforts to eradicate gender inequality will find its path blocked unless it explicitly tackles entrenched social norms, attitudes and practices in relation to marriage, as an integral component of its gender equality strategy (UNESCO, 2002a).

\subsubsection{Early Marriage in Africa}

The marriage or betrothal of children in parts of Africa and Asia is valued as a means of consolidating power relations between families, for sealing deals over land or other property, or even for settling disputes. Marriage may also be a way of maintaining ethnic or community relations. Children's rights as individuals in such situations are often disregarded; they may instead be seen purely as commodities at the family's disposal. Betrothals are traditionally not supposed to involve sexual relations until the girl reaches adolescence, but in reality husbands are rarely restrained (UNICEF, 2005).

Young girls may be forced or coerced to initiate sex even before it is traditionally permitted. In parts of South Asia, the practice of families using young girls to settle family feuds is a form of child marriage, which is 
driven by tradition and family ties. In Pakistan, the practice of 'vani' requires giving away girls in marriage to relatives of murder victims, as compensation for crimes committed, or to settle feuds between families or clans (Max-Planck-Gesellschaft, 2010).

Trends have been exhaustively examined courtesy of World Fertility Survey and DHS data. Analysts have detected two groups of countries: those where marriage age is rising, such as Kenya, Uganda, Zimbabwe and Senegal, and those where there is little change, including Cameroon, Cote d'Ivoire, Lesotho, Liberia and Mali. In several countries, over $40 \%$ of young women have entered marriage or a quasi-married union by the time they reach the age of 18 (World Fertility Survey \& DHS, 2008). By contrast, in only two countries are more than $10 \%$ of boys under aged 19 married. Early marriage is generally more prevalent in Central and West Africa affecting $40 \%$ and $49 \%$ respectively of girls under aged 19 compared to $27 \%$ in East Africa and $20 \%$ in North and Southern Africa. Many of these young brides are second or third wives in polygamous households (WHO, 2000b).

In some African countries, notably Botswana and Namibia, few girls marry in their teens. However, cohabitation is relatively common. While the trend towards later marriage is clear for the continent as a whole, there are some countries, such as Lesotho and Mozambique, 26 where the trend has been in the other direction (Max-Planck-Gesellschaft, 2010).

\subsubsection{Early Marriage in Ethiopia}

Ethiopia is predicted to be a home to more than 90,873,739 million people in 2012 and $44 \%$ of its population is under the age of 15 . It is one of the poorest countries in the world; approximately $81 \%$ of its population lives on less than US $\$ 2$ a day (Ethiopia Demographic Profile Prediction, 2012) and in 2005, life expectancy fell to 49 years (World Fact Book, 2012) mainly due to the growing HIV epidemic.

According to the "Essential Conditions of Marriage" (Section 2, Article 6-16) of the Revised Family Code (Proclamation, 2000) Article 7 specifies the legal marriage age of both boys and girls as follows: "Neither a man nor a woman who has not attained the full age of eighteen years shall conclude marriage." Despite this law, the country is known for one of the most severe crises of child marriage in the world. The Ethiopian DHS 2005 reports that $13 \%$ of girls in Ethiopia are married by the age of 15 (a slight decline from $14 \%$ reported by DHS, 2000) but those married before 18 remained high at $66 \%$. The median age also remained at about 16 years for the nation and 15 for the Amhara Region. The DHS 2005 report has further revealed that the practice of early marriage is decreasing among the younger generation. As for example, the proportion of women who got married by age 15 has declined from well over $30 \%$ among women to older than the age of 30 to $13 \%$ among women age $15-19$ years.

A study by the National Committee on Harmful Traditional Practices of Ethiopia (NCTPE, 2003) estimated the proportion marriage before the age of 15 to be $57 \%$. The same study showed that the practice occurs in its more extreme forms in northern Ethiopia, where girls are married as young as eight or nine years of age. In some instances, they are even pledged at birth. Although early marriage is widely practiced in many parts of the country, rates in Amhara and Tigray region are much higher than the national average (82\% in Amhara, $79 \%$ in Tigray, 64\% in Benshangul, 64\% in Gambella and 46\% in Afar) (NCTPE, 2003). A recent study conducted in two woredas of the Amhara region also showed that $14 \%$ of women were married before age $10,39 \%$ before age 15 , and $56 \%$ before age 18 (Population Council, 2004).

In Ethiopia, early marriage is seen as a way to improve the economic status of the family, to strengthen ties between families, to ensure that girls are virgins when they marry, and to avoid the possibility of a girl reaching an age where she is no longer desirable as a wife /"Qoma Qerech"/. The practice of early marriage is now / for a while/ understood to have very harmful effects on the health, psychological, physiological and socio-economic well-being of young girls /as well as for the newborns/. However, this knowledge is not broadly shared across most of the population (ibid).

Advocates for gender equality and the abandonment of harmful traditional practices (HTPs) argue that early marriage is one of the most harmful practices as it usually denies girls educational opportunities. This leads to poverty and economic insecurity and has a serious negative impact on their health and decision making capacities. It also reinforces other forms of gender-based violence and problems. Early marriage is mostly common in sub-Saharan Africa and South East Asia. It is rampant in Ethiopia, although prevalence varies from one region to another. At the national level, $62 \%$ of Ethiopian women aged 20-49 get married before the age of 18 (Bogalech, 2006).

One of the marriage arrangements common in Ethiopia is the arrangement made between two parents without the consent of the would be married couples. Early marriage is the principal indicator of women's exposure to the risk of pregnancy and higher fertility levels. The early age at marriage in a population is usually associated with a longer period of exposure to the risk of pregnancy and higher fertility levels. The early invitational child breaking associated with early marriage may also adversely affect the health of both women or mother and children. The duration of post-partum amenorrhea and postpartum abstinence affect the length of time a women is susceptible to pregnancy and thus determine the interval between births (EDHS, 2005). 


\section{Types of Early Marriage in Ethiopia}

a) Promissory Marriage- The promise is made between the two parents of the would be couples. Sometimes the promise can be done even before the birth of the child.

b) Child Marriage- Children under the age of ten years are wedded where the child bride is given to her in-laws immediately after the wedding ceremony commonly referred as "madego" or the bride/girl stays with her parents until the time agreed reached or assumes that she is matured enough to treat her husband; this is referred to as "meleles". But there is no strong method to respect the agreed time and no mechanism designed to punish or judge those who violate the promise. Due to this reason young girls are usually exposed to early marital sex (Pathfinderr International/Ethiopia, 2006).

c) Early Adolescent- This mostly takes place between the age of 10-15 of years i.e. Right at the start of puberty. After the wedding ceremony the bride has to prove her virginity. If not found virgin, the outcome is disgrace to her and more to her family/parents. The social implication on the girl and her parents is more of beyond imaginations (ibid).

\subsubsection{The Magnitude and Context of Early Marriage}

Current estimates show that approximately 82 million girls between 10-17 years get married before they reach 18 years. Of the 331 million girls aged 10-19 in developing countries (excluding China), 163 million get married before they are 20. Although early marriage is predominantly a female problem, a minority of boys may also be forced to marry early. There has hardly been any research conducted on young boys who marry early. In sub-Saharan Africa an d South Asia, on average only 5\% of men marry before they are 19 years old; in Europe, this figure is only $1 \%$ (Naana \& Sonita, 2003).

Early marriage is more prevalent in developing countries, particularly in the poorer rural sections of the community. According to a study conducted by Singh and Samara (1996) demonstrates that the higher the level of urbanization, the less likely it is that women marry before they reach 20 years. A close review of the evidence on the links between poverty and the pressure to marry early reveals that in wealthier countries, where girls have equitable access to education, further training and other employment opportunities, early marriages are rare. For example, in the USA, only $4 \%$ of girls marry before they are 19-years-old, in Canada this is about $1 \%$, while in the UK only $2 \%$ of girls make the choice to marry early.

Poverty is recognized as a major deciding factor for early marriage of girls especially in poorer households. Where girls are viewed as additional burden on family resources, they tend to be married off earlier as a family survival strategy. With the onset of the AIDS pandemic, poorer households are known to marry off their younger daughters at an earlier age to secure their future. In a vast majority of early marriages, a girl's young age is perceived to be a desirable attribute for marriage. Therefore the older the girl, the less likely will be her chances for marriage. Increasingly, in some parts of the world, early marriage is seen as a religious requirement to protect the sexuality of girls (Naana \& Sonita, 2003).

Although there is limited research on the determinants of early marriage, some notably elements it is often initiated and arranged by the family and includes an exchange of bride price or wealth. The specific value of the bride payment varied between societies. In agricultural or pastoral communities, this often consists of goods, money or livestock. These gifts are a central part of marriage transaction. However, they also reinforce the inequality of women and strengthen the notion that females can be exchanged or sold for the value that they bring into the receiving families (Singh \& Samara, 1996).

When a girl is married early, this reduces the economic burden on the family in caring for the girl, and also increases family assets. The payment of bride price can also enslave a girl in marriage in cases where families cannot afford to return the bride price if the girl chooses to leave an abusive marriage. In parts of Asia, a dowry is paid by the parents of the bride. Here, the financial consequences of dowry payments will be often greater for poorer and more vulnerable families. The general demand for younger brides will also force poorer families to want to marry their daughters early so as to avoid having to pay higher dowries for older girls. Since the size and quality of a dowry is linked to a woman's status in her marriage, younger girls from poorer families will invariably be more at risk if in-laws are dissatisfied with their dowries (ibid).

Greed has also become a major part of arranging early marriages, as parents and guardians are more motivated by financial benefits than by the well-being of their daughters. The inability to pay dowries can also put young girls at risk of early marriage or worse. In Bangladesh, poverty has often led to parents 'marrying off their daughters, when in reality they were being trafficked into prostitution (Erica Field, 2004).

Early marriage is often perceived as the only alternative for girls, particularly in situations of high insecurity and conflict such as in crowded refugee camps or where people are under the control of rebels in war situations marriage of a girl may be seen as a protective action, reducing her vulnerability to rape or kidnap. However, while recognizing that such reasons may derive from the need to protect girls, such marriages are still early and represent a grave denial of girls' sexual and reproductive rights (Angela, 2001).

In general, men tend to marry at a much older age than women or girls, and this is even reflected in some national laws where the legal minimum age for boys may be two or three years more than that for girls. For example in Ethiopia, Gabon and Burkina Faso, the legal minimum age at which a girl can marry is 15 , whereas 
for boys it is 18. Again the national minimum age of marriage is often only applicable in statutory marriages and is hardly ever enforced in religious or customary marriages (Singh \& Samara, 1996).

The notion of men as household heads means that most husbands are often more financially better off and older than their brides. Studies on 15-19 year old girls in Burkina Faso show that 35\% of their spouses were about ten years older than them. In other parts of West Africa, this figure is $54 \%$. A further $25 \%$ of male spouses were found to be over fifteen years older than their wives. The age difference between spouses has serious consequences on the power dynamics between them, resulting in unequal partnerships in the marriage, social isolation, low decision-making powers and coercion. It is common to find girl brides becoming widows at a very early age because of this age gap. In many communities, a young wife cannot inherit her husband's property when he dies, because of discriminatory customs, gender biases and her low social status within the family. She may even be blamed for his death (Singh \& Samara, 1996).

Comparative studies conducted population council in 2004 identified the Amhara region as having the highest prevalence, with $48 \%$ of rural married women and $28 \%$ of urban women married before the age of 15 . Types of early marriage in Ethiopia include promissory marriage, whereby a verbal promise is made at infancy or even childbirth by the parents to have their children get married; child marriage, in which children under the age of 10 are wedded; and adolescent marriage, which involves girls aged between 10 and 15 . In most cases, the child bride is taken to her in-laws immediately after the wedding; in other cases the parents agree that the girl stays with her parents until she is mature enough to live with her husband. In general, husbands are much older than their young wives (Bogalech, 2006).

According to Demographic and Health Surveys (DHS), which provide much of the current country-level child marriage data, child marriage is most common in the world's poorest countries. The highest rates are in sub-Saharan Africa and South Asia as well as parts of Latin America and the Caribbean (International Center for Research on Women (ICRW), 2006). A UNICEF study found that $48 \%$ of women between 15 and 24 were married before 18 in South Asia. Prevalence is 42\% in Africa (UNICEF 2005), and more than 60\% in some parts of East and West Africa (IPPF, 2006). In Latin America and the Caribbean, prevalence is 29\%, though some individual countries have much higher rates (UNICEF 2005). Child marriage is also common in the Middle East, where nearly half of girls younger than 18 in Yemen and Palestine are married (IPPF and UNFPA 2006).

The median age at marriage is rising around the world, including in developing countries (NRC/IOM 2005). In sub-Saharan Africa, 21 of 30 countries have seen an increase in the national age at marriage over the past several decades. This trend is largely attributed to the increase of girls' educational attainment and the increased participation of women in the labor force (NRC/IOM 2005). This increase in the age at marriage is occurring slowly and unevenly within countries, however, and many girls are missed by this trend.

Marriage during the teenage years is common in developing countries. Nevertheless, the situation varies greatly by country and region. Women are most likely to marry at a young age in Sub-Saharan Africa: In all but a few countries in that region, 60-92\% of all women aged 20-24 had entered their first union by age 20. Researchers also found that there is high prevalence of early marriage in a few countries in other regions: In Bangladesh, Guatemala, India and Yemen, 60-82\% of all women aged 20-24 had married by age 20. Although marriage during the teenage years is less common in Latin America, Asia, North Africa and the Middle East than in Sub-Saharan Africa, it is by no means rare. Typically, one-fifth to one-third of 20-24-year-olds in those regions had entered their first marriage by age 18, and one- third to one-half had married by age 20 (IPPF, 2006).

Even in France and the United States, $11 \%$ of all 20-24-year-olds had begun their first marriage or cohabiting union by age 18 , and $32 \%$ had done so by age 20 . Japan is exceptional in the rarity of marriage during adolescence: Only $2 \%$ of 20-24 year-olds had married by age 20. In a few developing countries, marriage by age 18 is relatively uncommon. The proportions of women married by age $18(10-14 \%)$ in Botswana, Namibia, the Philippines, Sri Lanka and Tunisia are similar to those in France and the United States, and the proportions married by age 20 (19-29\%) are lower (ibid).

Beginning the first marriage before age 15 is common only in Bangladesh and Niger, where about half of women aged 20-24 had married by that age. Nevertheless, the incidence of very early marriage ranges from $10 \%$ to $27 \%$ in seven Sub-Saharan African countries (Cameroon, Liberia, Mali, Nigeria, Senegal, Togo and Uganda) and six countries in other regions (Guatemala, India, Indonesia, Pakistan, Sudan and Yemen) (Singh \& Samara, 1996).

Reflecting these differences, the median age at first marriage (the age at which $50 \%$ of all women have entered their first marriage or union) shows wide variation with- in and across most regions. In general, women in Sub-Saharan Africa marry early, 11 of the 16 countries included from that region have a median age between 16 and 19 years. Yet, findings shows that there are exceptions to this pattern in Mali and Niger, countries with a predominantly Muslim population, where the median age at marriage is younger than 16, and in Botswana and Namibia, where the median age at marriage is about 24-25 (UNICEF, 2005). Although entry into the first union is late in Botswana and Namibia, the proportion of women having an early first birth is high, falling within the range found in other Sub- Saharan African countries. Widespread migration of men to 
obtain work is believed to be an important reason for the late age at marriage among both women and men in these countries (ibid).

The median age at first marriage is 20 or older in four of the 13 Asian and North African countries in our study, although there are a few countries in these regions with relatively low medians (Bangladesh, India and Yemen). Across Latin America, the median age at first marriage is relatively homogeneous. It is between 19 and 21 in all but four countries (Brazil, Colombia, Guatemala and Peru) (ibid).

\subsection{Causes of Early Marriage}

Despite the legal sanctions against marriage before age 18 and the growing awareness among leaders and educators that it is harmful to girls and their families, parents continue to insist upon marrying their daughters in their mid-teens and go to some lengths to resist all opposition. More than $80 \%$ of early marriage conducted is due to the tradition that peoples adhere to (UNFPA, 2006). The strongest reason for early marriage in the region is the desire or need to maintain the family's good name and social standing. For men in particular, the success of their children is a measure of manhood and community status, and a daughter's success rests in making a good marriage and linking her family to another family. Concern about a girl becoming pregnant out of marriage is also prevalent, though not nearly as significant as the issue of status and this could be a reason for early marriage. For some families, the desire to get 'macha' (money paid to the girl's family by the boy's family upon agreement to marriage) is an incentive (WHO, 2000a).

There is little doubt that parents are well aware of the negative consequences of early marriage, which are commonly discussed in communities. Though many condemn it in public, they seem compelled to continue its practice. This pursuit of tradition in the face of compelling negative evidence is common to most cultures and must be well understood when developing social change programmes (Bogalech, 2006).

\subsubsection{Economic Survival Strategies}

Poverty is one of the major factors underpinning early marriage. Where poverty is cute, a young girl may be regarded as an economic burden where one less daughter is one less mouth to feed (WHO, 2000a). Parents encourage the marriage of their daughters while they are still children hoping that the marriage will benefit them both financially and socially, while also relieving financial burdens on the family. In traditional societies in Sub-Saharan Africa, the bride's family may receive cattle from the groom, or the groom's family, as the bride price for their daughter (UNICEF, 2001).

In traditional societies- where infant mortality was very high and survival depended on a family's ability to produce its own food or goods for sale, child marriage helped to maximize the number of pregnancies and ensure enough surviving children to meet household labor needs. Additionally, poor families tend to marry off girls at the same time to help reduce the burden of high marriage ceremony expenses (ibid).

\subsubsection{Socio-Cultural and Religious Values}

In communities where child marriage is prevalent, there is strong social pressure on families to conform. Failure to conform can often result in ridicule, disapproval or family shame (Kabeer, 2005). Invariably, local perceptions on the ideal age for marriage, the desire for submissive wives, extended family patterns and other customary requirements, are all enshrined in local customs or religious norms. In many contexts child marriage is legitimized by patriarchy, and related family structures, which ensure that marriage transfers a father's role over his girl child to her future spouse. The marriage or betrothal of children in parts of Africa and Asian is valued as a means of consolidating powerful relations between families, for sealing deals over land or other property, or even for settling disputes (UNIFPA, 2006).

\subsubsection{Value of Virginity and Protection of Young Girls}

Early marriage is one way to ensure that a wife is protected, or placed firmly under male control; that she is submissive to her husband and works hard for her in-laws' household; that the children she bears are legitimate (UNICEF, 2001). On the other hand, for many societies that prize virginity before marriage, early marriage can manifest itself in a number of practices designed to protect a girl from unsanctioned sexual activity. In North-East Africa and parts of the Middle East in particular, control may also include the practice of female genital mutilation (FGM) to restrict sexual pleasure and temptation. Some parents withdraw their girls from school as soon as they begin to menstruate; fearing that exposure to male pupils or teachers puts them at risk. These practices are all intended to shield the girl from male sexual attention, but in the eyes of concerned parents, marriage is seen to offer the ultimate protection measure (Toubia, 1993).

In Wars and civil conflicts, parents resort to child marriage as a protective mechanism or survival strategy. Displaced populations living in refugee camps may feel unable to protect their daughters from rape, and so marriage to a warlord or other authority figure may provide improved protection. For young girls, orphans or children separated from their parents or relatives, the only way to survive and to get protection is to get married (Integrated Family Health Program, 2009). 


\subsubsection{Insecurity}

A study conducted by UNICEF, (2005), situations of insecurity and acute poverty, particularly during disasters such as war, famine or the HIV and AIDS epidemic, can prompt parents or careers to resort to child marriage as a protective mechanism or survival strategy. In some parts of sub-Saharan Africa the HIV and AIDS epidemic has led to an increase in child marriages. This could be due to families' desires to secure the future of their daughters. Among some populations which have been disrupted by war (e.g. in Burundi, Somalia, Northern Uganda and Afghanistan), marrying a young daughter to a warlord or someone who can look after her may be a strategy for physical security or family support. In the worst cases girls are abducted or kidnapped by armed militia or rebels and forced into temporary marriages which amount to "a combination of child prostitution and pure slavery." Displaced populations living in refugee camps may feel unable to protect their daughters from rape, and so marriage to a warlord or other authority figure may provide improved protection (Singh \& Samara, 1996).

\subsection{Consequences of Early Marriage}

There tends to be a relationship between age of marriage, level of education, poverty, and health: poorer, less educated girls tend to marry earlier and also tend to have poorer health. The following consequences tend to flow from early marriage.

\subsubsection{Effect of Early Marriage on Girls’ Education}

The school is the most important institution outside the family involved in socializing young people into all dimensions of adult roles and responsibilities. More years of schooling have been associated with many positive outcomes, including later ages of marriage, lower fertility, and healthier and better-educated children, economic development (UNICEF, 2005). However, early marriage inevitably denies children of school age, their right to the education they need for their personal development and their preparation for adulthood, and their effective contribution to the future wellbeing of their family and society. Indeed, married girls who would like to continue schooling may be both practically and legally excluded from doing so. The essence of the rights to education and to health is that they facilitate and ensure the effective enjoyment of other human rights (USAID, 2008).

For a number of poorer families, the potential rewards of educating daughters are too far off, and therefore, their education is not recognized as an investment. Families perceive that a girl's education will only benefit her husband's household, and not her parents. Additionally, some parents believe that girls do not need an education for their roles as wives and mothers, that education undermines cultural practices, and it teaches the girl to reject tradition (USAID, 2008).

However, there is a saying that whenever you educate a woman, you educate a nation. Education, even at a basic level, is not only about livelihood and technical skills but more importantly provides social 'connectedness' or aptitude which enables one to access key resources to alleviate poverty (Lewis, 2006). By interacting with others, individuals acquire the social skills and personal capacities needed to access resources and opportunities, and to form social networks for support and assistance when required in the future. Individuals can also develop their self-esteem and confidence to voice their opinions and to take control over their own actions, lives and bodies. Other positive benefits of education are linked to improved reproductive health and child survival and welfare, (Naana \& Sonita, 2003).

Educated women are more likely to have a say in decision-making regarding the size of their families and the spacing of their children. They are also likely to be more informed and knowledgeable about contraception and the healthcare needs of their children (Lewis, 2006). Adolescent girls who marry outside their communities tend to lose the close friendships they had formed in their parental homes, and often become quiet and subdued. This means that even where girls have developed social networks, they are unable to access them from their marital community (USAID, 2008).

The universal right to education has been affirmed by the world's governments for more than 50 years, most recently by the Millennium Development Goals adopted by the 191 member states of the United Nations in 2000. However, some 115 million children among them 62 million girls are still denied this right. According to data from (UNICEF, 2004) outside of the developed world, only $76 \%$ of all boys and $70 \%$ of all girls attend primary school. Husbands of young wives are often older men, who expect their wives to follow tradition, stay home and undertake household and child care duties. A girl may be unable to go against her husband's wishes and the husband's family may refuse to invest their scarce resources in the wife's continued schooling (UNICEF, 2004).

Some schools often have a policy of refusing to allow married or pregnant girls or girls with babies to return. They may believe that it will set a bad example to other pupils or that other parents will be angry to see the school go against the traditional beliefs. Even if they do permit girls to return, the school environment rules, timetables and physical conditions can make it too difficult for a girl to attend school and perform her duties as wife and mother at the same time. Bullying and abuse by teachers, pupils and other parents can further reduce girls' self-confidence and sense of security, forcing them to give up on schooling (Lewis, 2006). 
When girls drop out of school to get married, there is a knock-on effect for the community as a whole, and for future generations. Evidence suggests that children of young, uneducated mothers are less likely to have a good start to their education, do well in class or continue beyond the minimum schooling. Their daughters especially are likely to drop out, marry young and begin the cycle again (ibid).

\subsubsection{Effects of Early Marriage on the Well-being of Women}

Early marriage has severe consequences for the health and well-being of girls and women. In the Ethiopian context, some of these include:

\subsubsection{Marital Instability, Abandonment and Early Widowhood}

About $27 \%$ of marriages in urban areas and $19 \%$ in rural areas had ended in divorce or separation. Of those that had married more than once, for the $56 \%$ their first marriage ended either because they were too young or 'not interested' in the marriage. Many girls run away from unhappy marriages only to be sent back by their parents (UNICEF, 2004).

Some desperate women who have been forced into marriage try to run away or take other avenues to leave their spouses; others are abandoned by their spouses. However, the girls and women are usually left with the responsibility of raising children without the husband or family's financial support, thus making them more likely to live in poverty. In many cultures, husbands are often many years older than their young brides, and consequently die while the girl is still young (Lewis, 2006). Furthermore, the girl's families are unlikely to accept her back once she has become widowed. In cultures that permit polygamy, the youngest co-wife is required to care for elder co-wives. This relationship is sometimes a daughter/mother relationship, but in many cases the elder wives view the younger with bitterness and resentment (UNICEF, 2001).

\subsubsection{Termination of Education}

According to a study conducted in UNICEF (2005) almost every setting, better-educated women are more likely to use contraception, bear fewer children, raise healthier children, make better decisions for themselves and their children and to make greater economic contributions to the household (USAID, 2008). More than $80 \%$ of girls aged 12 to 14 were attending school. However, among female students attending school, 28\% cited marriage and 19\% cited childrearing obligations as their reasons for quitting school. Four percent cited their husbands' disapproval of their school attendance as a reason. Married adolescent girls' inability to negotiate safer sex and other social pressures represent a critical channel of vulnerability to HIV infection (Bogalech, 2006).

\subsubsection{Inability to Plan or Manage Families -}

Statistically, women who marry early are likely to bear more children. Among our respondents, those married under 15 averaged 4.96 children; those married between 15 and 17 had 4.15 , and those over the age of 18 averaged 3.12 children. Young mothers exercise less influence and control over their children and have less ability to make decisions about their nutrition, health care and household management (ibid).

\subsubsection{Health and Related Outcomes of Early Marriage \\ 2.3.3.1. Early Child Bearing and Unwanted Pregnancies}

Young girls who get married will most likely be forced into having sexual intercourse with their, usually much older, husbands. This has severe negative health consequences as the girl is often not psychologically, physically and sexually mature. Early marriage is associated with early child bearing. Young married girls are under tremendous pressure to prove their fertility in the first year of marriage. Girls, who marry young, inevitably have children early, and have many children, because their knowledge of contraception is poor and their power to negotiate its use is weak (UNFPA, UNIFEM and OSAG; 2005).

\subsubsection{Domestic Violence and Sexual Abuse}

As young girls are often married to men who are much older than themselves, the age difference tends to reinforce the powerlessness of the girl, who is thus at greater risk of abuse and less likely to assert herself. Young married girls are more likely to be beaten or threatened and more likely to believe that a husband might sometimes be justified in beating his wife. Women who believe that they are more likely to get married before age 18 than those who believe that they have no justification. Child brides are often more susceptible to domestic violence (USAID, 2008). In Egypt, data indicates that $29 \%$ of married adolescents were beaten by their spouses or their spouses and others. Of these, $41 \%$ were beaten when they were pregnant (Naana \& Sonita, 2003; Population Council, 2004).

\subsubsection{High Maternal Mortality and Morbidity}

The World Health Organization estimates that the risk of death following pregnancy is twice as great for women between 15 and 19 years than for those between the ages of 20 and 24 . The maternal mortality rate 
can be up to five times higher for girls aged between 10 and 14 than for women of about twenty years of age. Pregnant adolescents face far more health problems than older women, particularly single girls who often receive less prenatal care. Adolescents are far more susceptible to suffering from anemia than adults, which greatly increase the risk and complications linked to pregnancy. They are equally more at risk of malnutrition, high blood pressure linked to pregnancy and eclampsia than women who are over the age of 20 (Singh \& Samara, 1996).

\subsubsection{Increased Risk of Contracting Sexually Transmitted Diseases and HIV/AIDS}

A girl is physiologically more prone to contracting HIV than a male, as her vagina is not well lined with protective cells and her cervix may be penetrated easily (WHO, 2000a). Fear of HIV infection, has encouraged men in some African countries to seek young virgin and therefore uninfected partners. On top of pregnancyrelated complications, young married girls are also at high risk of contracting sexually transmitted diseases and HIV/AIDS (UNICEF, 2001). Young married girls are even at higher risk because their older husbands may already be infected in previous sexual relationships. Furthermore, the age difference between the girl and the husband and her low economic status make it almost impossible for the girl to negotiate safe sex or demand fidelity. Early marriage usually means that young girls enter marriage without adequate information about critical sexual intercourse, contraception, sexually transmitted diseases, pregnancy and childbirth (Naana \& Sonita, 2003).

\subsubsection{Impact on Sexual Health of Women}

Young girls can face considerable physical pain associated with sexual inter-course as a result of the physiological immaturity of their sexual organs. Complications due to pregnancy at a young age frequently include obstetric fistula (perforation of the bladder or bowel, due to prolonged labor) (United Nations Population Fund (UNFPA) \& Engender Health, 2003).

\subsubsection{Lack of Power}

It is hypothesized that women who are married as children have less decision making power than women whose marriage is delayed until adulthood. They don't have ability to make decision on their own health care, contraception, household budget, daily household purchases, visit to family and friends etc. They have little power in relation to their husbands and in-laws (UNICEF, 1997).

\subsubsection{Reinforcement of Gender Stereotypes and Roles}

The lack of other opportunities and the powerlessness that often accompanies early marriage combine to perpetuate the gender roles of girls and women and reinforces cultural traditions that support early marriage as a desirable practice.

\section{Methodology of the Study Research Design}

In social science research, the use of quantitative and qualitative approach in integration is advisable to crosscheck and supplement each other and to enrich the results. This study employs both quantitative and qualitative research techniques. Hence the study follows sequential design (explanatory sequential design). Data collected through questionnaire would be manipulated quantitatively through pie-charts, tabular and graphically. Moreover the data graphed and pie-charted briefly explained to clearly show the result of the research on addressing the identified problem. The techniques and data collection instruments, procedures and data analysis methods used are discussed briefly in the subsections below.

\subsection{Data Sources}

The necessary data sources used to assess the prevalence, causes and impacts of early marriage on women in the study area (in this case Gozamine woreda) were primary and secondary data sources. Primary sources were obtained through structured questionnaire, in-depth interview, and focus group discussion whereas secondary data sources were obtained from reports, pamphlets, magazines, other researches carried out by individuals, GOs, NGOs.

\subsubsection{Secondary Data Collection Methods}

Secondary sources of data which were fundamental and related to the research study were collected and obtained from different governmental and non-governmental organizations found in gozamine woreda. In general, this data gathered through the consultation of different institutions. Such as:

- The kebele health extension office- periodical and non-periodical reports of health extension officers concerning early marriage was assessed. Different manuals whereby they used to teach the society are also employed.

- The Woreda Women, Children, and Youth Office: different training manuals prepared by the office and other offices which they used to train the society, periodic reports concerning the report. 
- The Woreda Culture and Tourism Office; survey study conducted in the woreda by the office, periodic reports and pamphlets prepared by the office were used.

- Woreda Police Station: periodical reports which shows the number of parents who gave advice to prevent early marriage, training materials prepared by the office.

- Woreda Health office; different training materials concerning early marriage,

- Woreda Education office; different periodic and special reports that show that show the list of students who are expected to be married and the number of early marriages aborted due to continues effort of the sectors.

- Government communication offices periodic and non-periodic reports, published and unpublished documents were investigated. Hence it also used to assess the existing situation of early marriage, to assess whether early marriage is decreasing or increasing from year to year, whether the prevailing causes well known by the concerned bodies or not.

\subsubsection{Primary Data Collection Instruments}

Initially, an extensive review of relevant documents and literature was undertaken, first to place the study in a demographic, social and health context, and secondly to gather information for the development of the study instruments. Based on the review of international, national, regional, and district level documents and research reports, three types of instruments were developed to collect qualitative and quantitative information on the prevalence, causes and consequences of early marriage. These included a structured individual questionnaire, in-depth interview, and focus group discussions.

\subsubsection{Quantitative Method of Data Collection: The Structured Questionnaire}

The individual questionnaire is the most important instrument, as it was used to collect most of the quantifiable information on the prevalence, causes and its associated problems on ever married women under the age limitation (15-50 years of age). This instrument was used to collect quantitative information on respondents' socio-economic and demographic characteristics, issues relating to the prevalence, causes and consequences of early marriage on women, and on the status of women in the society. The questionnaire was administered to a representative sample of 350 respondents in the specified age group.

Open ended and close ended questionnaires were prepared for ever married women who are within the age limitation / 15-50/ in the Amharic language of the local people, and in the form of questions, whereby the interviewer took note of the responses. Questionnaires were initially developed in English language but further translated to Amharic by the researcher himself and further developed by Debre Markos university language department English teachers. Questionnaires were discussed with Amharic professionals and highlevel educators at Debre Markos University. The married women questionnaire consists of 26 questions. A general guideline for each questionnaire application was developed and a pretesting of the questionnaires was conducted at the field level.

\subsubsection{Qualitative Method of Data Collection}

The qualitative methods of data collection where by this research included are the combination of in-depth interview and focus group discussion. Moreover, each instrument of data collection for the qualitative method is briefly explained as follows:

\section{In-Depth Interviews}

A semi-structured interview was administered for 6 (2 from Wonka, 2 from Yebo and 2 from Kebi) married girls and women of the selected kebles. These interviewees selected from these kebeles were among the respondents of the questionnaire so as to make more clear and detail the data and information obtained through questionnaire. The interviewees are deeply asked and re-asked based up on the replay they forward. The interview guide was structured according to the following main themes:

- Perception of the status of early marriage in the study area,

- Perception of the problems associated with early marriage,

- Existing programs or interventions against early marriage, and sources of information about the impacts of early marriage,

- The causal factors of early marriage in the area,

- the prevalence and magnitude of early marriage in the study area,

- $\quad$ Socio-economic and health problems associated with early marriage.

\section{Focus Group Discussions}

A FGD guide was developed to elicit information on the prevalence, causes and impacts of early marriage on women in the study area. The guide was used to administer FGD participants among the participants of the questionnaire. 
The main themes included in the focus group guide were: the status of early marriage as perceived by each group; health, and socio-economic problems; the main causes of early marriage in the area; the prevalence and magnitude of early marriage; sources of information concerning on the consequences of early marriage; and what effective solutions to be taken to handle the problem. In addition to these, the FGD guide attempted to address factors that impact negatively on women due to early marriage, parental attitudes, and suggestions for intervention strategies.

\subsection{Quantitative Data}

\subsubsection{Sample Design}

The primary consideration in the sample selection for any study is to include representative and adequate numbers of samples in order to perform a meaningful analysis. To ensure this, three different sampling designs were used. The three kebeles were selected through area cluster sampling technique.

As pointed out earlier, the main focus of the study was to generate information on the prevalence, causes and consequences of early marriage on women in Gozamine Woreda East Gojjam Zone Amhara Region. A list of kebeles in Gozamine woreda was obtained from the Woreda administrative office. As a result of this 25 rural kebele administrative and two sub-urban were identified. Hence the woredaś kebeles were listed and classified in to eight clusters by using their geographical location. Indeed a total of three geographically clustered kebeles were selected for the purpose of this study through simple random sampling method.

Moreover, after the kebeles have been selected through area cluster sampling technique individual respondents were selected through random sampling technique. The list of married women in the kebeles was obtained from health extension workers. Hence from the total listed married women, those who were under the age limitation (15-50 in the case of this study) were further screened. Then from this screened and listed married women, 341 were randomly and 9 (kebele women children \& youth office head, women league president, and women association head) were purposively selected to respond for the questionnaire. Finally, the kebele women association chair person; women league president; and women, children and youth office head were selected through purposive sampling technique. Hence the sample size for this study was determined using the formula:

$$
\mathrm{SS}=\frac{\mathrm{Z}^{2} \times(\mathrm{p}) \times(1-\mathrm{q})}{\mathrm{C}^{2}}
$$

Infinite Population (where the population is greater than $50,000)$

$\mathrm{SS}=$ Required sample size

$\mathrm{Z}=$ Confidence level at $95 \%$ (standard value of 1.96 )

$\mathrm{P}=$ Estimated prevalence of early marriage in the study area.

$\mathrm{C}=$ Margin of error at $5 \%$ (standard value of 0.05$)$

$$
\mathrm{SS}=\frac{3.8416 \times .5 \times .5}{0.0025}
$$

According to National Committee on Traditional Practices of Ethiopia (2003), Pathfinderr International/Ethiopia (2006) the prevalence of early marriage in the region is $50 \%$ which is among married women half of them were married before the legal marriage age. Hence $\mathrm{P}=50 \%=0.5$.

$\mathrm{SS}=384$ hence this formula is used when the population is greater than 50,000 and our population is below this number, we should use another formula.

New sample size $=$ Finite Population (where the population is less than 50,000)

$$
\text { New } S S=\frac{\frac{s s}{\left(1+\left(s s_{-1}\right)\right)}}{\text { Pop }}
$$

The population is 2455

$$
\text { New } S S=\frac{\frac{384}{(1+(384-1))}}{2455}
$$

New SS=333

The sample size is further increased by $5 \%$ to account for contingencies such as non-response or recording error. Hence, $333 \times 0.05=\mathbf{3 5 0}$.

\section{Population of the Study}

Wonka kebele has 1206 total number of married women. Among which 180 are divorced and living alone without a husband and the rest women (1026) are living with their husbands. From these 1206 women 125 are below and above the age limitation which is $15-50$ years. Hence 1081 women are under the population sample frame.

$1081 \times 350 / 2455=154$ samples has been selected randomly 
Yebo kebele has 997 total numbers of married women. Amongst these women 103 are divorced and the rest (894) are living with their husbands. From this total number of married women 68 in number are below and above the age limitation (15-50). Hence 929 women are under the population sample frame.

$929 \times 350 / 2455=133$ samples has been selected randomly

Kebi kebele has 492 total numbers of married women. Amongst these women 79 are divorced and the rest (413) are living with their husbands and about 47 are below and above the age limit (15-50). Hence 445 women will be under the population sample frame.

$445 \mathrm{X} 350 / 2455=63$ has been selected randomly

In general about 341 randomly selected respondents and 9 purposefully selected respondents totally about 350 respondents will be participated to respond for the questionnaire. For the purpose of in-depth interview amongst from the three kebeles nine interviewees three from each kebele were selected through random sampling technique. The FGDs has been conducted in each kebele having a group from 8-12 too.

\subsection{Qualitative Data}

\subsubsection{Techniques for Qualitative Data Collection}

The qualitative information was collected through Focus Group Discussions (FGDs) and in-depth interviews with married women. Review of relevant literature in the selected study area was used as a source of ideas for elaborating on the FGD and key informant findings. The FGDs participants and key informants were married women.

The in-depth interviews were carried out on ever married women at the community (kebele) levels. The FGD and the key informant interviews were carried out to dig out deep and detail information from individuals who responded for the questionnaire and to search for information that supports or substantiates findings obtained through other data collection instruments (questionnaires and document review).

\subsubsection{Sampling for the Qualitative Survey}

An attempt was made in the qualitative survey to collect data by selecting two interviewees from each Kebele. Those, interviewees selected from each kebele were selected through purposive sampling technique. Hence the qualitative information was collected from three kebeles of the Woreda. All kebeles sampled were in the south-western parts of the zonal capital Debre Markos city, as selected through area cluster sampling which covers Wonka, Yebo and Kebi kebeles. In each of these kebeles, one FGD ( 3 in total) was conducted having a group number of 8-12 members. The key informant interviews were carried out in each of the 3 kebeles selected through purposive sampling method. This was done by purposively selecting six women from the list of women who responded for the questionnaire. Two interviewees from each kebele, six interviewees in total from the three kebeles were interviewed.

\subsection{Preparation and Fieldwork}

\subsubsection{Recruitment and Training}

Grade 10 completed six females were trained and recruited to fill the questionnaire. The training was carried out in Wonka (for Wonka \& Yebo kebeles dwellers), and Kebi (for Kebi kebele dwellers) to get interviewers and supervisors (in this case development agents of each kebele) who are familiar with the study sites. Grade 10 completed females who are dwellers of the kebeles but, who have no permanent job living with their parents were selected to take the sample properly and fill the questionnaire, and most of them had a little experience in data collection activities by participating in kebele development works in mobilizing and teaching the community in soil and water conservation activities, family planning and reproductive health, providing free community development services at their kebele, and compile reports.

The training was carried out in Wonka and Kebi kebeles. By which 6 interviewers for the questionnaire were recruited and trained for one day on key issues related to procedures and techniques of data collection, handling of respondents, and techniques of sample selection. Rehearsal interviews for the questionnaire and demonstrations were held and discussions initiated, based on the training. The recruited questionnaire interviewers were specifically briefed on techniques of handling respondents and on the contents of the guidelines prepared to conduct for quantitative approach.

\subsubsection{Pretest}

Pretest of survey instruments is important and helps to detect both content and structural errors in the questionnaire, allowing for necessary corrections before undertaking the actual exercise. The pretest was conducted in Wonka and Kebi kebeles. In Wonka kebele an attempt was made to cover areas of two villages (gotes) (Kechin woneth and Deber), where as in Kebi one village (gote) was covered. These villages / gotes are situated near to the kebele office where by the training is conducted on those ever married women who are under the age limitation (15-50years of age). Twenty five questionnaires (fifteen in Wonka and ten in Kebi) were completed during the pretest, by ever-married women. During the pretest, in addition to technical scrutiny, questionnaire facilitators were instructed to carefully identify ambiguous and inappropriate questions 
that were not clear or were offending to most respondents. Thus, valuable input was obtained during the operation, which was used to modify the questionnaire, and a final version was produced.

\subsubsection{Data Collection}

Initial steps in data collection involved identification of respondents for each survey and the administration of the various (questionnaire, interview, and FGD) survey instruments. The researcher himself checked filled-in questionnaires and made on-the-spot checking to see whether interviewers conducted successful interviews and recorded appropriate responses. In addition to the researcher, development agents were voluntarily assigned hand in hand with their work (in the sub-kebeles whereby they are assigned by their office) to coordinate and supervise the overall data collection activities with no pay due to their positive interest to assist the researcher and to ensure correct implementation of the sampling techniques.

Respondents were asked for oral consent prior to participating in the study. There were no incentives for participating in the FGDs, which were conducted within the premises of kebele administration offices.

\subsection{Data Processing}

\subsubsection{Editing and Coding}

Usually interviewers are strictly instructed to fill in questionnaires in accordance with the guidelines provided and to protect against inconsistencies. Different scholars vividly said that interviewers occasionally overlook some of these elements, which is why the researcher assigned himself to review the questionnaires and identify incorrect and inconsistent responses and make appropriate corrections immediately. Apart from all these data quality control mechanisms, editing and coding activity was carried out by the researcher to review for completeness and appropriateness in coding of responses.

\subsection{Data Analysis}

Having had distributed the questionnaires, conducting FGDs, interviewing the interviewees, assessing and collecting necessary secondary data from the Woreda Women, Children and Youth Office, Culture and Tourism Office, Education Office, Police Station, and the court; the filled questionnaires have been coded. After the data have been collected, coded and edited entered the computer (SPSS version 19) for analysis, it has been organized and the analysis and interpretation of data had been started to determine the validity and reliability and the achievement of the already identified problem with the purpose of the study. The researcher uses different types of data analysis methods.

Hence the quantitative data analyzed through percentage, frequency descriptive statistics, and mean. The qualitative data was also analyzed. Hence the quantitative data had been analyzed through percentage, descriptive statistics, and frequency methods whereas the qualitative data generated from interviewees and FGD participants had been analyzed through narrative analysis. The analyses also show widely-held views and explore the varying perspectives on early marriage.

\subsection{Organization of the paper}

This research paper is organized in six chapters. Chapter four presents the background information such as age, sex, religion, marital and educational status and source of information of respondents. Chapters Four through six present the survey findings. Chapter five presents the prevalence of early marriage, the characteristics which show its prevalence and related practices, the causes and consequences of early marriage. The last chapter is a summary and conclusion of the main findings and makes recommendations arising out of these results.

\section{Background Information of Survey Respondents}

Background information on age, sex, religious condition, current marital status, educational status and other demographic characteristics of respondents are essential for the interpretation of findings and understanding of results later in the paper This chapter provides the general background information of respondents contacted in the quantitative survey, including informants' age distribution, religious background, level of education, marital status, and age at first marriage. 


\subsection{Age Classification of Respondents}

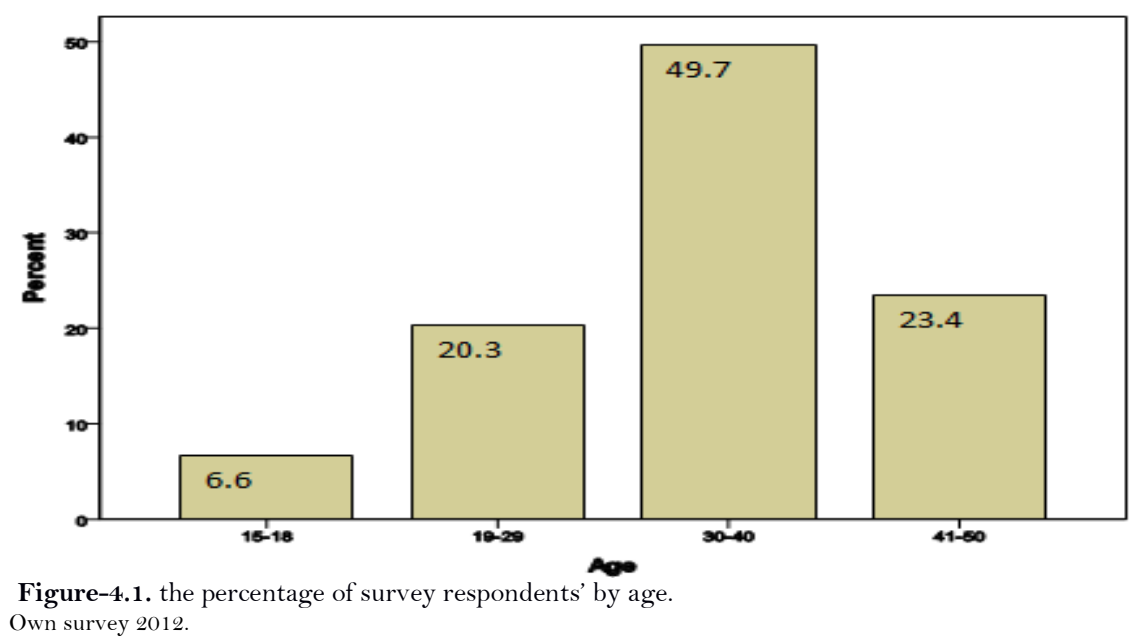

The age distribution of survey respondents is presented in Table 4.1. Due to the nature of the study (causes and consequences of early marriage on girls and women), ever married women between 15-50 years of age were included under this study. Survey respondents of ever married women constitute $6.6 \%$ under the age of $15-18,20.3 \%$ of the respondents were under the age of 19-29. Among the total number of the respondents $49.7 \%$ were under the age of $30-40$, and others $(23.4 \%$ of the respondents) were under the age of $41-50$. This result showed that most $(49.7 \%)$ of the respondents age was from 30-40 years of range followed by $23.4 \%$ within 41-50 years of range.

\subsection{Religious Background of Respondents}

This study has been conducted in Gozamine woreda Eastern Gojjam Administrative Zone in selected three rural kebeles selected through area cluster sampling technique. Most often rural kebeles of this woreda are totally dominated by orthodox Christians. Hence the populations covered under this study were totally members of the Orthodox Christian Church (100 percent).

\subsection{Level of Education}

Education is a vital instrument to change societal understanding, wellbeing and to develop self-esteem. Educated mothers let their girl children go to school and prevent them from early marriage. Whereas, illiterate mothers mainly in rural areas make their children to marry off early. The children of old, uneducated mothers are also less likely to attain high levels of education, perpetuating cycles of low literacy and limited livelihood opportunities. When girls' education is disrupted to get them married early, they also lose valued opportunities to other benefits of formal education. This makes the smooth transition from adolescence into adulthood for the majority of married girls very problematic.

Where the transition to adulthood is managed and supported, the majority of young women and girls become more empowered to effectively play their future roles as women, mothers, wives, wage earners and active citizens of their country. Education is known to play a vital part in this transition. Yet girls of primary school age not only are precluded from school but also lose their rights as children. Child marriage transforms a school girl into an adult, even if she is only seven years old (IPPF, 2006). Illiterate women are not in a position to acquire knowledge from various pamphlets and other printed media which helps them to change, lead and direct their backward way of living in a better condition.

Respondents were asked about their educational status to see the effect of early marriage on women socioeconomic status. The graph below shows that respondents in the study area were unable to read and write. This study reveals that among the respondents $37.7 \%$ of respondents were illiterate, $38.3 \%$ of survey respondents were learned basic education, $16.3 \%$ of survey respondents were educated $1-4$ class, $4.6 \%$ of survey respondents were educated $5-8$ class, $2 \%$ of respondents were attended $9-10$, and only $1.1 \%$ of survey respondents were joined preparatory school (from grade 11-12). Amongst the survey respondents none of them graduate diploma and above. In general most of survey respondents under the study area did not accomplished primary school secondary cycle. 


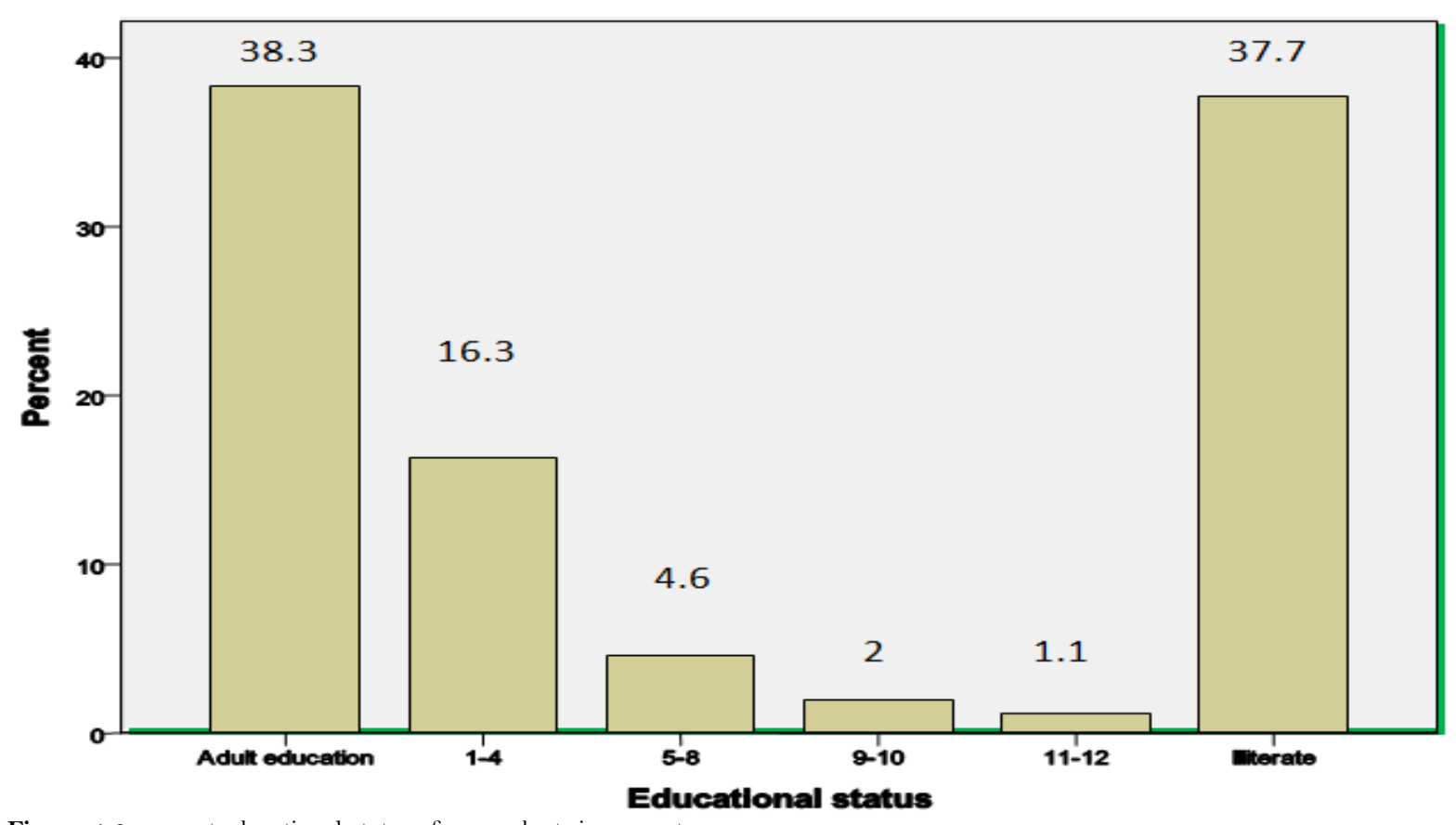

Figure-4.2. current educational status of respondents in percent.

Own survey 2012

The survey respondents were asked about the reason for their school dropout and for being illiterate. Most of them do not enroll in regular program from the beginning and others were enrolled but dropped out due to different multi-faceted problems. Thus, $76.3 \%$ of the survey respondents dropped out due to early marriage; $64 \%$ of survey respondents dropped out due to child bearing; $57.7 \%$ of the respondents dropped out due to parents did not allow to enroll; $42.6 \%$ of the respondents were drop out as inability to get assistance to educate them; $71.1 \%$ of the respondents dropped out due to longer hour domestic work and burden; $40.3 \%$ of the respondents dropped out due to the absence of assistance to pursue their education; $55.7 \%$ of the respondents dropped out due to their husbands lack of willingness for their wives to continue education.

In rural areas, husbands, in-laws and the community believe that educated wives are not in a position to manage the home; husband and the children as well as they are not submissive to their husband and to her inlaws. These factors are decisive to hinder women's life but, there are other supporting factors that play minor role in affecting their life such as $9.1 \%$ of women dislike to join school, but rather need to marry at their early childhood without knowing its draw back due to childhood to decide based up on reason, and $1.1 \%$ of respondents dropped out because of inability to pass to the next grade,

\subsection{Marital Status of Respondents}

Forty-five percent of all first marriages in Ethiopia end in divorce or separation within 30 years, and twothirds of women who divorce do so within the first 5 years of marriage. Divorce has been a common and largely accepted practice in Ethiopia for centuries. As early as the 16th century, divorce was referred to as the 'custom of the country' (Pankhurst, 1990). Divorce due to early marriage is more common in the Amhara region than the other regions of the country, and more common among Christians than among Muslims (Central Statistics Authority, 1993). There may be several explanations for this. People who practice the Muslim religion in Ethiopia may have a stronger tradition of the indissolubleness of marriage than do the people who practice the Christian Orthodox religion. This may be partly true because the religious authority plays a larger role in Muslim marriages than in Christian Orthodox marriages (Mekonnon, 1986).

Young girls widowed as children, some as young as eight years old deprived of their human rights to health, education, protection from sexual violence and economic exploitation. These violations persist in spite of their rights being enshrined in the CRC, the CEDAW and the Beijing Platform for Action which have been agreed by almost all UN member states. In the very poorest communities, for example in rural Afghanistan, Ethiopia, Yemen and Tanzania, thousands of little girls have been forcibly married, often before they reach the adolescent, and widowed before they reach adulthood. They will have suffered from, social, health, physical and psychological, premature pregnancy and giving birth long before their bodies are ready for such events. They have been denied to enjoy their childhood time. With no one to protect them, their futures are miserable as they bear the triple disabilities of gender, marital status, and being underage (Margaret, 2012). 


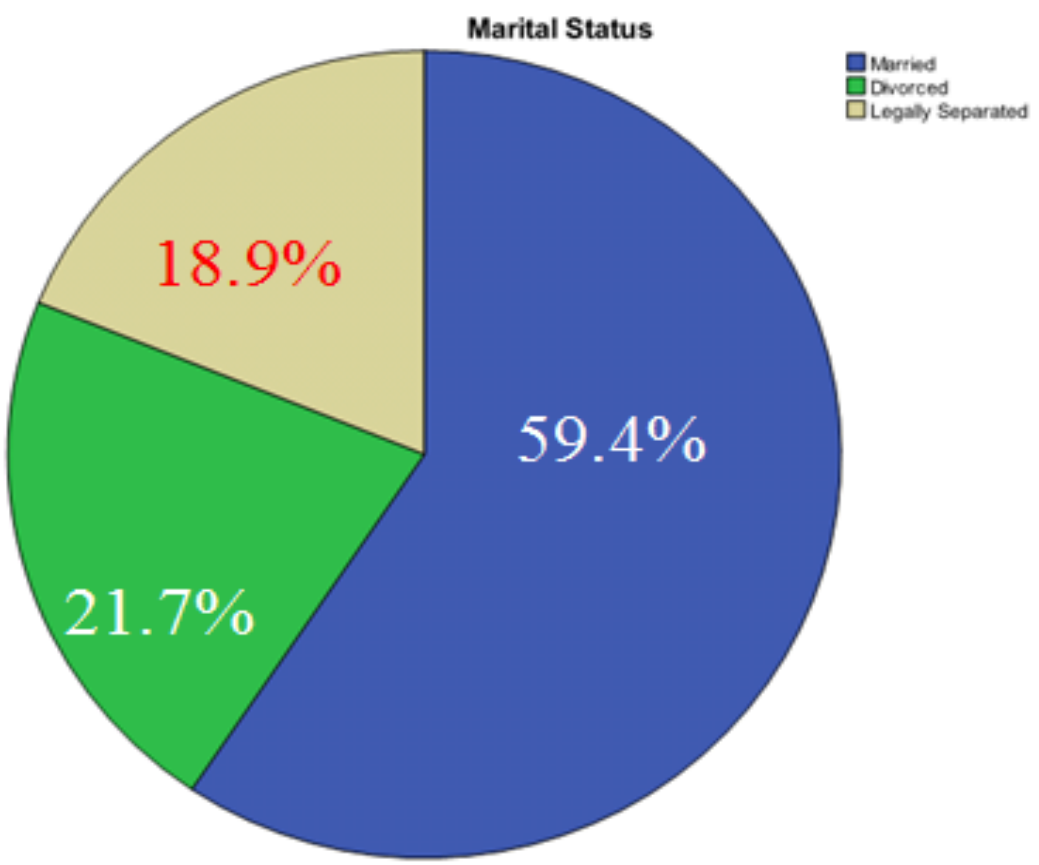

Figure-4.3. Current marital status of respondents. Own survey 2012.

As shown on the above figure the number of married respondents of this survey research is 350 . Among this figure $59.4 \%$ of the respondents were currently married and $21.7 \%$ of the respondents were divorced and the remaining $18.9 \%$ of respondents were widowed. This figure shows that there exists high prevalence of divorce and widowhood.

\subsection{Access to Mass Media}

Information is vital for people to change the existing prevalent situation of early marriage. According to the April, 28 2004 Ethiopia radio and television program, early marriage is highly prevalent in the region and is causing multi-faceted problem on girls. Most girls get into this union at their young age with their families good will but some are interested to marry early without the knowledge of its draw backs on them and some do it because too young to make right decision-making.

Studies show that mass media motivates the society towards positive behavioral change across the world including early marriage which is highly tightened by traditional practices and thoughts. In this survey, information was collected about the availability and usage of electronic and printed mass media as a source of information for the dwellers of the study area. The data obtained from survey respondents on the graph below show that $54.9 \%$ have no access to electronic and printed mass media whereas only $45.1 \%$ of the respondents have access to mass media. This shows that information dissemination concerning early marriage has limitation to address rural women who are taking the lion's share of its effect.

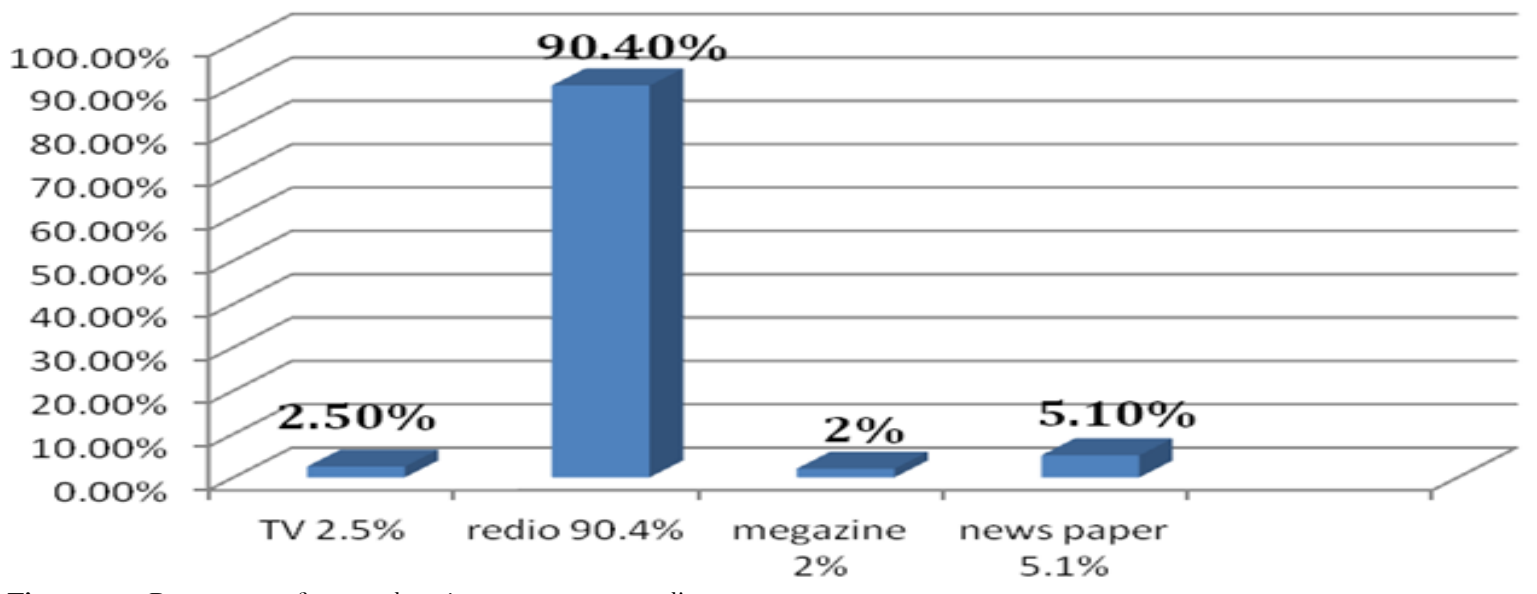

Figure-4.4. Percentage of respondents' access to mass media. Own survey 2012. 
Consequently, amongst of the surveyed respondents who have access to mass media $(45.1 \%$ of the respondents) only $2.5 \%$ have access to television, $90.4 \%$ have access to radio message, $2 \%$ have access to magazine, and $5.1 \%$ have access to newspaper. This result shows that due to their illiteracy, women are denied of the exposure to printed media. Even though some of the respondents are literate, the access to printed media is too slim and others have no time to read any printed media, they are busy on domestic works such as rearing and bearing children, managing the family, rearing domestic animals, cooking food and other different works which is considered their only job according to the society's belief.

In general more than half $(54.9 \%)$ of respondents had no access to both electronic and printed media, whereas below half (only $45.1 \%$ ) of the respondents of women had the exposure to printed and electronic mass media. This shows that the information dissemination about the prevalence, causes and consequences of early marriage on women is highly limited. This suggests that rural women are disadvantaged in terms of access to information through mass media. Moreover, as the majority of them are illiterate, the access to print media is also very limited. Some respondents clarified that though some of them have the exposure to mass media; programs have no clear idea or thematic area on the issue and on languages which consider the understanding level of the rural illiterate women.

\subsection{Causes of Conflict among Spouses}

Conflict among couples creates a problem on the family. When mothers and fathers are not able to communicate to create conducive environment for the family it leads to divorce and family displacement. Moreover youngsters and children might be forced to go to street. This creates a huge and irreversible problem on the life of the children. Children exposed to further labor exposure at their early age which was their age of education. Uneducated citizen could and would not be productive for a certain country. This is because, they cannot be able to fit and easily manipulate the global technological advancement.

The survey respondents were asked about whether they quarrel with their spouse or not, how often do they quarrel, and their reason for the quarrel. The result shows that $62.6 \%$ of couples quarrel Some times, $9 \%$ always quarrel, and only $28.4 \%$ of couples do not quarrel living with love and deep fonder. The result also shows that even though there are different reason that could be a source of their quarrel the main reasons reported by the respondents $(58.3 \%)$ were due to early marriage, $52.9 \%$ were due to marital rape, $47.4 \%$ were due to domestic violence, $27.7 \%$ were due to the need for divorce, and $16.6 \%$ were quarreled due to sexual dissatisfaction among the pairs.

Data obtained from the surveyed respondents of ever married women domestic conflict among couples consequences miss management of common property and unwise use of domestic resources. More often the husbands accumulate their own deposit by selling the common property to prevent their wives equal distribution of property during divorce which resulted from conflict. The wives only receive what is remaining at hand at the time of divorce.

\subsection{Sources of Information at the Kebele Level}

Mainly in rural area such as gozamine woreda where the problem is pronouncedly manifested substantial and up to date information is important to change the existing situation data collected from survey respondents show that $76.9 \%$ do know that whether there are institutions and/ or organizations that teaches the public about the prevalence, causes and consequences of early marriage in their kebele, $15.7 \%$ of the respondents said that there are no institutions and individuals who teach them about the issue, and the remaining $(7.4 \%)$ reported that they had no knowledge about who teaches people of the kebele regarding the issue.

In a decentralized administration, different governmental institutions have been established and launched at the kebele level. These governmental institutions and civil servants in the institutions are responsible to teach the society about traditions that harm the society. As a result $48.3 \%$ of the respondents responded that teachers and school clubs are their source of information at the kebele level, $84.3 \%$ responded that health institutions mainly health extension agents and the 


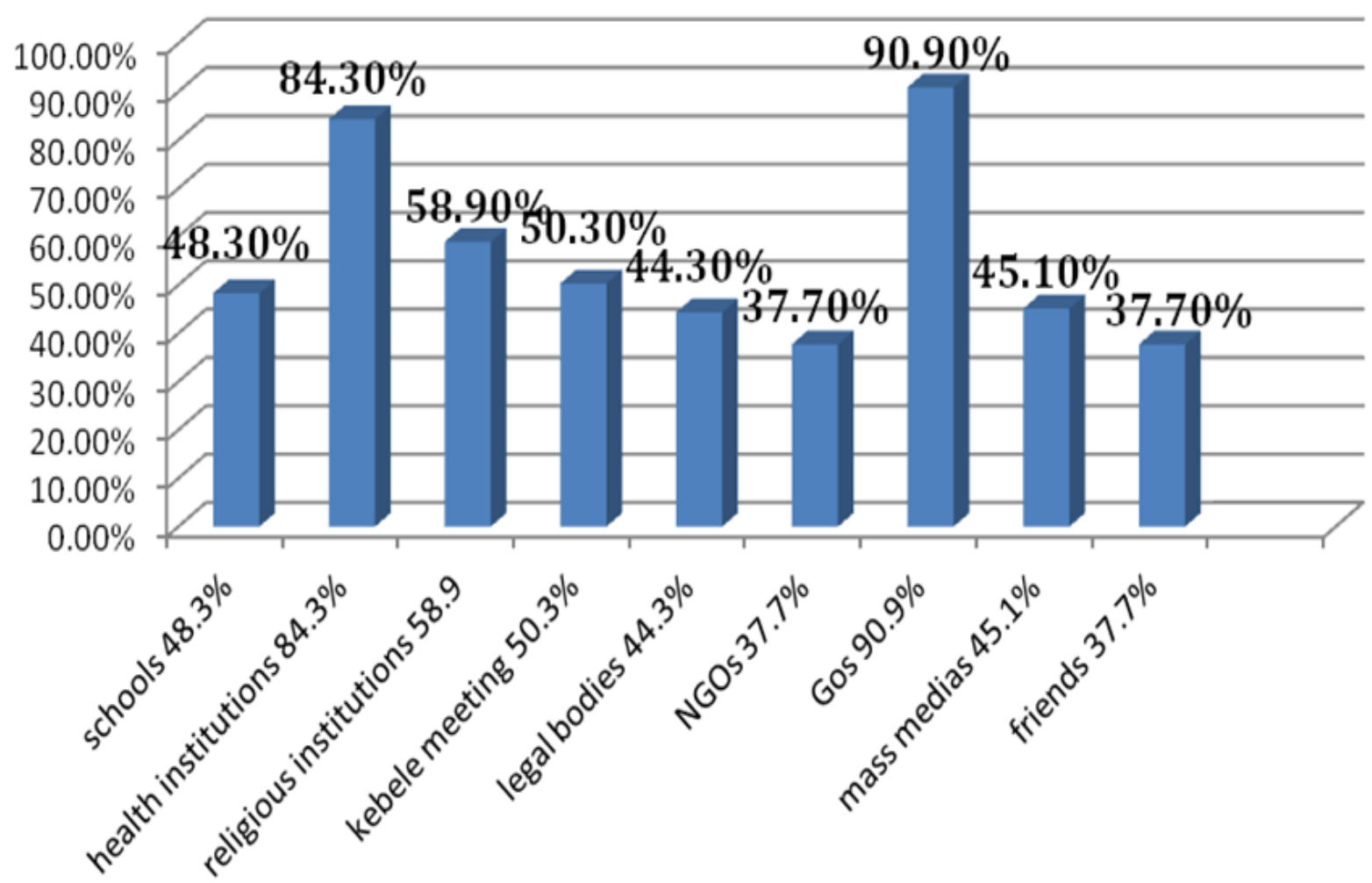

Figure-4.5. percentage of respondents' source of information at kebele level.

Own survey 2012 .

nearby health care centers, $58.9 \%$ of them responded that their source of information are religious institutions and leaders (in this case churches and priests); 50.3\% responded that kebele officials and meetings are their source of information; $44.3 \%$ of them responded that it is community policing officers and legal bodies who are teaching the impacts of and its occurrence before the age of $18 ; 37.7 \%$ of the respondents said that NGOs convey different messages about the issue; $90.9 \%$ GOs convey different messages and give training about early marriage; $45.1 \%$ of the respondents responded that mass media is their source of information; and $37.7 \%$ of the respondents said that their source of information are their friends. Mainly kebele health extension agents, community policing officers, school teachers and kebele officials take the lion's share.

\section{Findings of the Study}

\subsection{The Prevalence of Early Marriage}

Many international conventions, the Federal Democratic Republic of Ethiopian constitution and the Amhara region Revised Family Code signify that 18 years have been established as the legal age at first marriage. Any form of marriage before this minimum marriage age qualifies as early marriage. This survey study tried to assess the prevalence, causes and its associated problems in the Gozamine woreda Amhara Region.

This chapter begins by presenting the study finding on the prevalence of early marriage in the study area, age at first marriage, and marriage without one's consent followed by quantitative and qualitative survey data regarding age at first marriage, the best indicator of the prevalence of the practice of early marriage, clearly show the main causes of early marriage in the study area and finally this chapter discusses the consequences of early marriage on women and girls health and socio-economic aspects.

\subsubsection{Age at First Marriage}

Ethiopia has one of the highest rates of early marriage in the world, with one in two girls marrying before her 18th birthday and one in five girls marrying before the age of 15 (Pathfinderr International/Ethiopia, 2006). Actual age at first marriage is the best indicator of the prevalence of early marriage in a certain area. Due attention was given for both quantitative and qualitative surveys to collect reliable information on age at first marriage in Gozamine Woreda.

\subsubsection{Findings of the Quantitative Survey}

Age at first marriage classification was made to depict the picture at various physiological and puberty stages. In certain societies, many believe that women reach puberty at age 12 and others think that age 15 is ideal for marriage. In the following analysis, the age at first marriage was categorized by taking into account 
all these considerations, and we believe that the distribution shown on Figure 5.1 below provides a meaningful picture about the prevailing situation in the study area.

Early marriage is prevalent in Ethiopia in many regions. In north Ethiopia little girls as young 7 years are married to teenage boys and grow up together in his parents' house till it is believed that she is ready to have sex or first menstruation (UNICEF, 2001). According to Pathfinder International/Ethiopia (2007), early marriage is extremely prevalent in some regions of Ethiopia; in Amhara, 50\% of girls married by the age 15; and $80 \%$ married by the age of 18 . It is also indicated that the mean age at first marriage in rural areas of Gojjam was 14.6 years which is lower than the legal age.

fig. Respondents age at first marriage

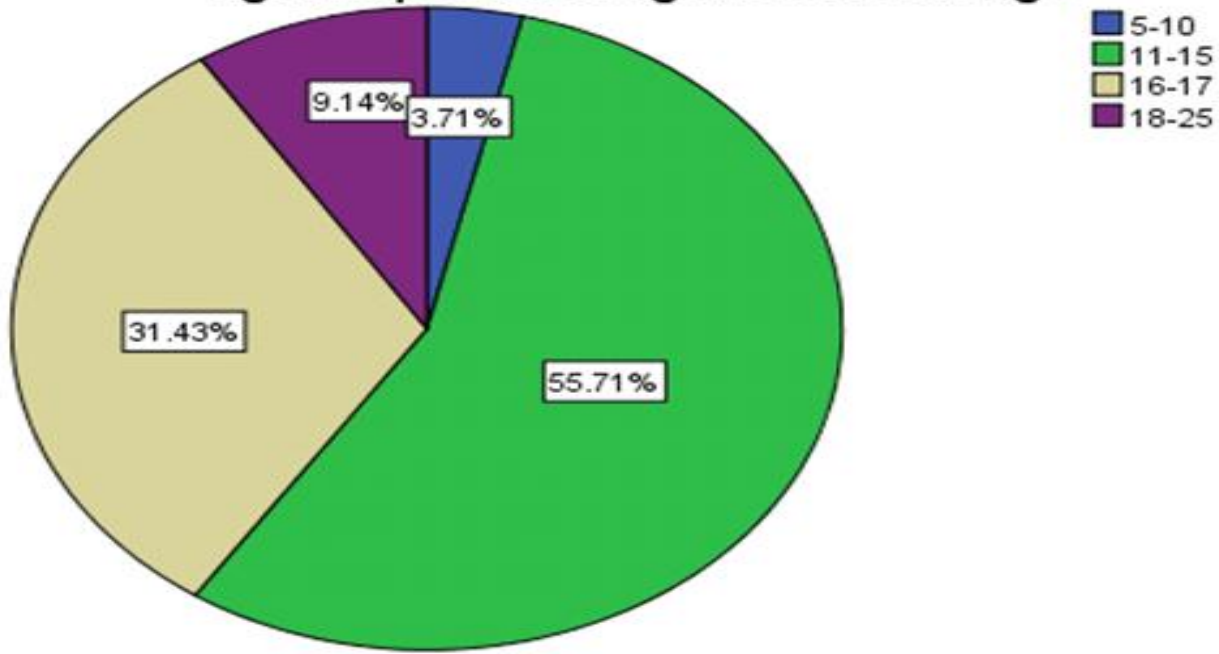

Figure-5.1. percentages of respondents' age at first marriage.

Own survey 2012 .

East and west Gojjam are the main zones whereby early marriage is highly prevalent and creating different multifaceted social, economic, psychological and health problems. Since Gozamine Woreda is found in eastern Gojjam Zone; the prevalence of early marriage was remarkably causing multi-faceted problem on women and girls. Hence, 13 respondents (3.71\%) were married when they were 5-10 years of age; 195 respondents $(55.71 \%)$ were married when they were $11-15$ years of age; 110 respondents (31.43\%) were married when they were 16-17 years of age; 32 respondents (9.1\%) were married when they were 18-25 years of age; and none of the survey respondents were married at the age of 26 and above. As a result about $2.9 \%$ of the survey respondents started sex below the age of 10, $67.1 \%$ from $11-17$ years of age, $30 \%$ from 18 years of and after.

Early marriage is highly associated with early pregnancy and child birth when women are not physically, mentally, and psychologically strong enough to shoulder the burden of delivery and its consequences including child bearing and rearing. The quantitative data obtained from the survey respondents showed that among women who married early, about $1.1 \%$ of ever married women did not know when they delivered their first child, $38 \%$ delivered under the age of $12-16 ; 36.9 \%$ delivered under the age of $17-18 ; 22.6 \%$ delivered within the age of 19-25; and 1.4\% of the respondents of ever married women were delivered after their 26 .

\subsubsection{Findings of the Qualitative Survey}

According to the report of the baseline survey on harmful traditional practices by National Committee on Traditional Practices of Ethiopia (NTCPE) (1998) the average marriage age for women in Amhara Region is 14.5. A report by the former Women's Affairs Office of the Amhara Region (Information Bulletin 2003) however, showed that the lower age of first marriage (12.5 years).

Interviews and FGDs were conducted in the three kebeles (six married women two from each kebeles were interviewed and three FGDs were conducted having a member of ten participants on average (Wonka 12, Yebo 10 \& Kebi 8 members) and three moderators one for each group) to assess necessary detailed information that reinforces the data obtained from the questionnaire. Relevant information was obtained from the respondents of the interview and FGDs participants.

Different secondary documents were collected and analyzed as part of qualitative data of the study that confirm the prevalence of early marriage in Gozamine woreda. According to Gozamine Woreda Culture \& Tourism Office (2004) different types of marriage are conducted in the woreda; such as exchange marriage $16 \%$; religious marriage 20\%; registered legal marriage only $2 \%$; and $62 \%$ of marriage is arranged by community elders. Moreover, $66 \%$ of marriage is arranged by parents' good will, and only $34 \%$ of marriage has been conducted by the groom and brides interest.

Among marriages' conducted in the study area, $32 \%$ of the society married before they were ten; $37 \%$ married under the age of 11-17 and only $31 \%$ of the societies married after they are 18 . In general, among 
women married, $69 \%$ married before they were 18 which is below the legal marriage age (Gozamine Woreda Culture \& Tourism Office, 2004). The information obtained from interviewees and FGD participants showed that the age at first marriage has a significant improvement. In the earlier period parents were wedded their girl child before the legal marriage age. But now as a result of continues effort of governmental institutions and employees, the legal awareness of the people has been improved. As a result the age at first marriage has magnificent improvement but there is still a problem.

\subsubsection{Age Difference between Couples}

Young girls may also be encouraged to marry older men, due to the perception that an older husband will be able to act as a guardian against behavior deemed immoral and inappropriate. Previous studies have shown that men with younger wives live longer. While it had long been assumed that women with younger husbands also live longer, in a new study Sven Drefahl from the Max Planck Institute for Demographic Research (MPIDR) in Rostock, Germany, has shown that this is not the case. Instead, the greater the age differences from the husband, the lower the wife's life expectancy. This is the case irrespective of whether the woman is younger or older than her spouse (Max-Planck-Gesellschaft, 2010). Age differences result in significant differences in life experience and outlook. Many studies have also shown that age affects an individual's attitude and behavior. People who are in the same age bracket get a long life together and understand each other more easily than in traditional societies where there is a large age difference. A couple's age difference is believed to affect the level of their communication, mutual understanding, and agreement on various familial issues. It also affects the balance of influence and control within the family, giving an older man considerably more control than that held by his young wife (Pathfinder International/Ethiopia, 2007). Ever-married women were asked for information on the age difference between themselves and their spouses at the time of first marriage. Among the respondents of ever married women $4.6 \%$ were equal with the groom, $94.8 \%$ were younger than the groom, and only $0.6 \%$ of the brides were older than the groom.

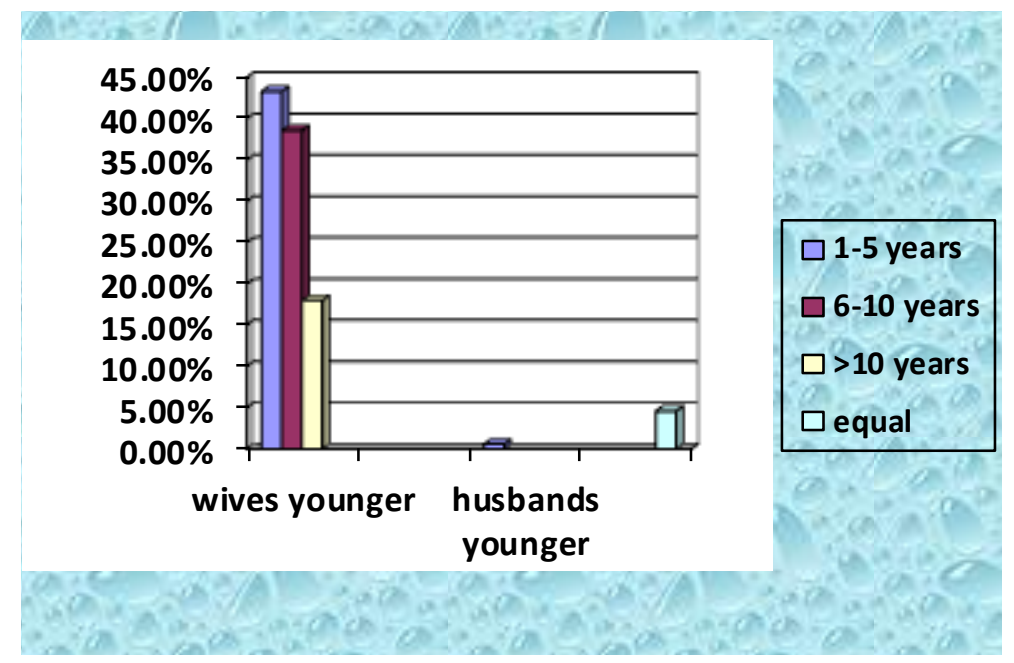

Figure-5.2. percentage of age difference among couples at first marriage. Own survey 2012.

Of those respondents who married an older husband (94.9\%), 43.4\% of the survey respondents of ever married women, the age difference among their spouse was from 01-05 years; $38.6 \%$ of the survey respondents of ever married women, the age difference among their spouse was from 06-10 years of ages; and for 18\% the age difference among their spouse was greater than 10 years. On the other hand, among those survey respondents of ever married women who was older than their spouse at their first marriage, about $0.6 \%$ were older by 1-5 years of age.

Age difference was also an issue during the FGDs. Discussants confirmed that early marriage usually involves large spousal age differences, which in most cases limits the autonomy and decision-making ability of married women. It is normal and is accepted in the study area that husbands should be slightly older than the wife. But in certain cases, much older men are married to younger girls due to economic and associated reasons. They do believe that whenever the husband is older than his wife, he can easily advise her and manage the common property efficiently considering that she cannot do so.

\subsubsection{Marriage without Girl's Consent}

The right to 'free and full' consent to marriage is recognized in the Universal Declaration of Human Rights with the recognition that consent cannot be 'free and full' when one of the parties involved is not sufficiently mature to make an informed decision about a life partner. More than $55 \%$ of the ever-married 
women have been pressurized into marriage. The sources of that pressure were predominantly fathers $(91 \%)$ and mothers (88\%), followed by community elders $(22 \%)$ and others in the community (Pathfinder International/Ethiopia, 2007).

Consent and age are the two most "Essential Conditions of Marriage" according to the Revised Family Code (Proclamation of 2000). Hence, the practice of early marriage violates the rights that are legally and constitutionally regarded as the first two most "essential conditions of marriage".

Among those women married early, some are forced into this union, others are simply too young to make an informed decision even do not remember whether they were asked about their consent or not. Others such as father, mother, and nearby relatives provide consent on behalf of the child. The child does not have the opportunity to exercise her right to choose her mate. As a result, early marriages could be regarded as forced marriages. Young girls are forced or pushed into marriages by their parents, relatives, community elders, and the like.

Many believe that an exemplary marriage is characterized by the mutual understanding and respect the couple has for each other. This normally happens when the couples have entered into the marriage willingly and without the influence of a third party. Willingness reflects the individual's commitment and readiness to keep the marriage intact. In line with this, effort was made to see if respondents entered the marriage with or without the influence of a third party. In other words, married women were asked if they were pressurized to get into the union and who created that pressure. The result is presented in Figure 5.3.

As can be seen from Figure 5.3 below, only $5.7 \%$ of respondents were married by their good will; $58.3 \%$ respondents were married due to the influence came from parents; $10.6 \%$ of respondents reported they were influenced by relatives to marry; $23.4 \%$ reported influence from community elders; who in most cases act as intermediate negotiators between the brides' and grooms' families and work to get them heard and respected, and about $2 \%$ of the respondents do not know who arranged and decided their marriage.

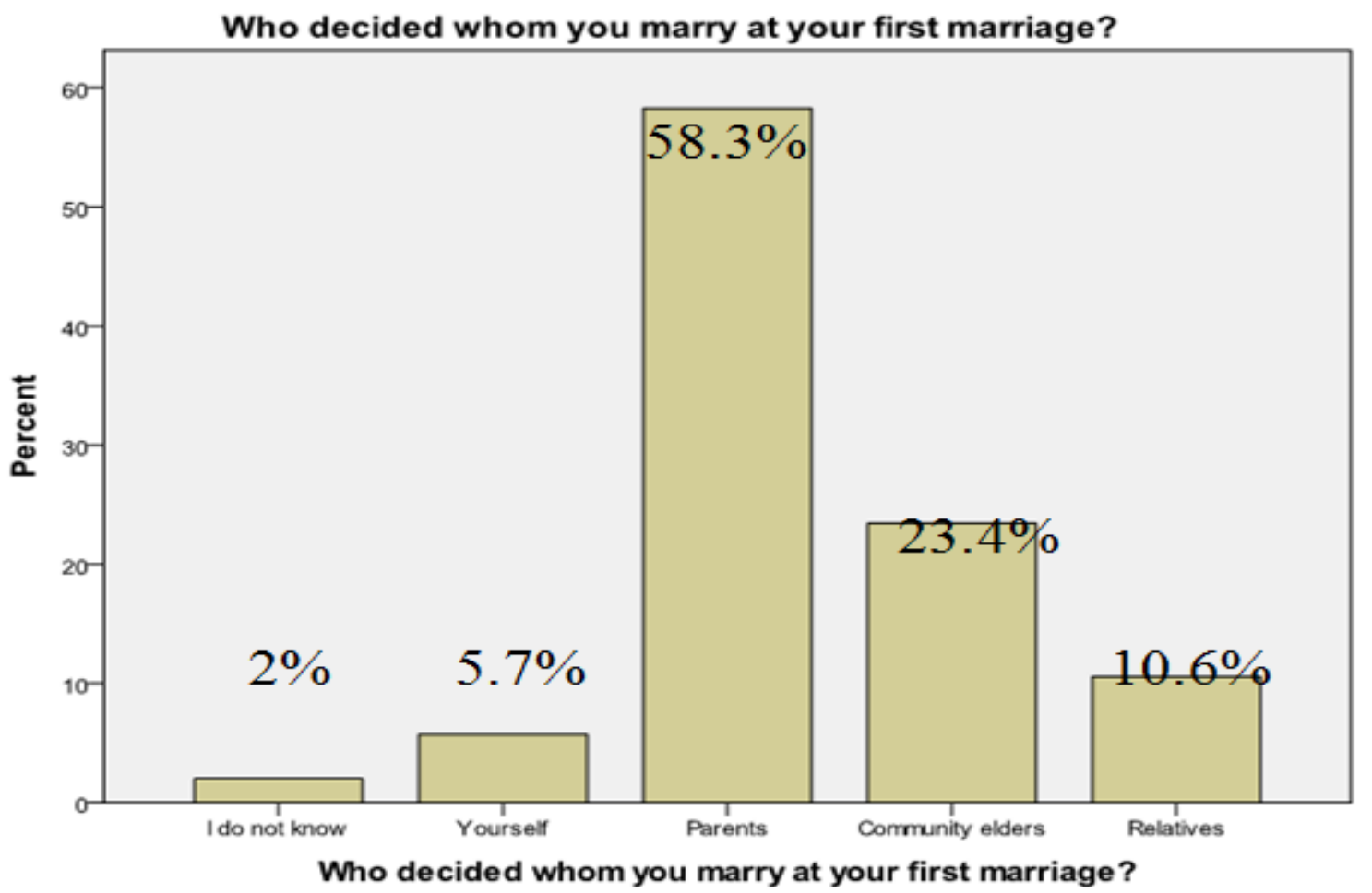

Figure-5.3. percentage of the decision to marry off girls early.

Own survey 2012.

In general, parents, community elders, and other relatives play a significant role in pushing girls into marriage. This finding shows the severity of the problem and shed light on the extent of violation of individual human rights. Young girls are being influenced to get into marriage without their consent and interest.

The role played by parents gone beyond pressure to marry to include the choice of the husband. Even the girl does not know him yet. Making the decision to marry, arranging the marriage and preparing marriage ceremony are out of her knowledge. Survey findings show that $14.3 \%$ of respondents know their partner only facially; $9.7 \%$ of respondents know their partner only by name; $11.7 \%$ of respondents know their partner both by name and facially; and most of the respondent $64.3 \%$ do not know their partner either by name or facially. In the study area, most of the ever married women do not know their spouse prior to marriage either by name or facially. Thus, couples were in doubt to communicate each other, to talk frankly on common matters, which further leads to domestic violence, and in-laws and husbands dominance. 
The majority of ever married women (61.4\%) were not asked for their consent further probing was made among those who had been informed prior to the wedding whereas $16 \%$ of respondents did not remember whether they were asked or not, and only $22.6 \%$ of respondents were asked about their consent prior to their marriage but only $35 \%$ were voluntary on the marriage whereas $65 \%$ refused to marry. Consistent with findings related to parental and relative influence, most of the young women who were asked for consent were not really for the sake of their consent. All of the respondents who were asked for their consent but refused marry were made to marry.

This shows that parents told brides simply not to get for their true consent because they told them when the marriage left with days or weeks. In the study area, hence it is rural; disagreement or refused to marry is interpreted as disrespect and is regarded as indecent behavior. Many lack the courage to disagree for fear of rejection by family members and the community at large. It further shows that, although marriage is supposed to be a joyful occasion, uniting two families and creating a new domestic unit to continue the hope and values of the society, in reality, for young girls, the event often represents a serious abuse of their personal human rights.

\subsubsection{Current Situation of Early Marriage in the Study Area}

Different international conventions such as CEDAW, CRC and national conventions and the newly revised family code of the region declares that 18 is the legal minimum age for marriage. Any form of marriage below this minimum age is considered as early marriage. But the society mainly living in the rural area where mass Medias and other means of information are limited; the perpetrators do not know the right minimum legal marriage age.

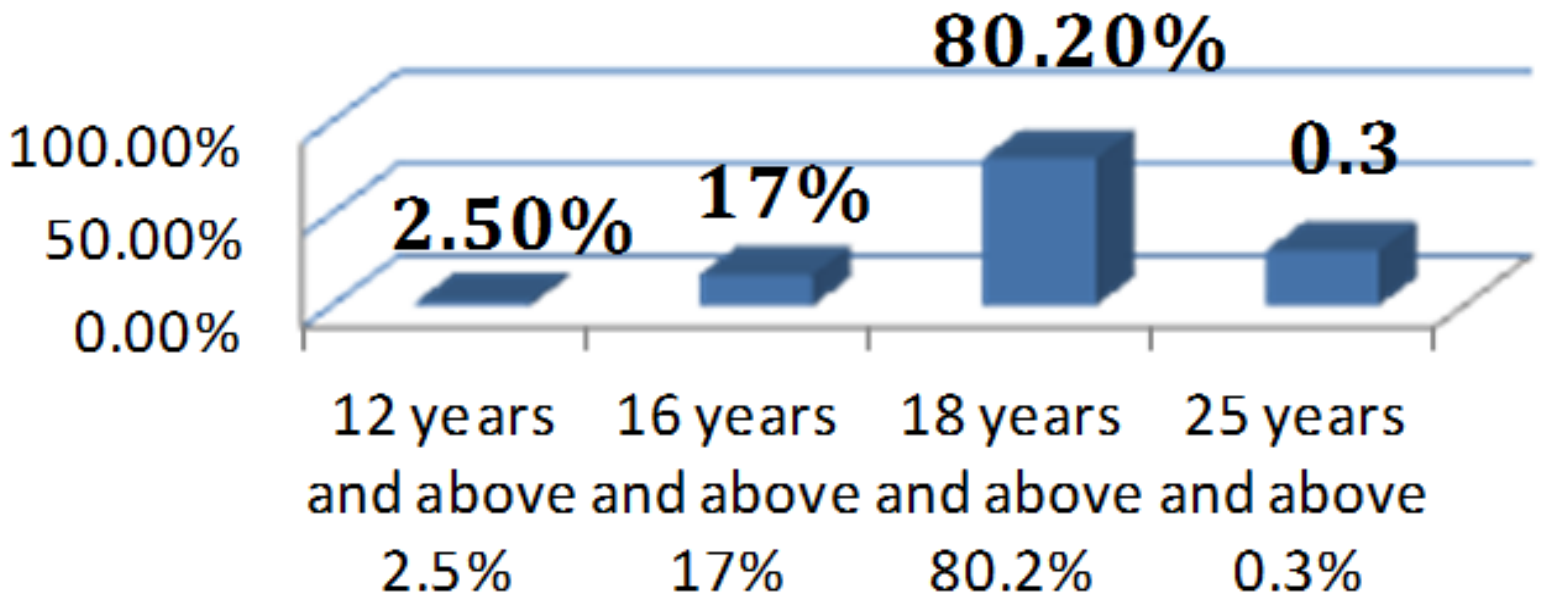

Figure-5.4. Percentage of current minimum legal marriage age.

Own survey 2012

Respondents were asked whether they do know this minimum legal marriageable age or not, but $85.4 \%$ knew it and $14.6 \%$ do not know the minimum legal marriage age. The data obtained from survey respondents showed that $2.5 \%$ said that age 12 and above is the minimum legal marriage age, $17 \%$ said that 16 years and above is the minimum legal marriage age, $80.2 \%$ of the respondents said 18 years and above; $0.3 \%$ said 25 years and above is the minimum legal marriage age.

The graph shown below represents the current usual marriage age of girls in the study area. The survey respondents were asked about the current usual marriage age of girls in gozamine woreda. Thus, $0.6 \%$ of the respondents responded that 5-10 year is usual marriage age, 7.7\% said that 11-15 years is the usual marriage age; $14.3 \%$ responded that $16-17$ years is usual marriage age; $77.4 \%$ responded that $18-25$ years is usual marriage age. 


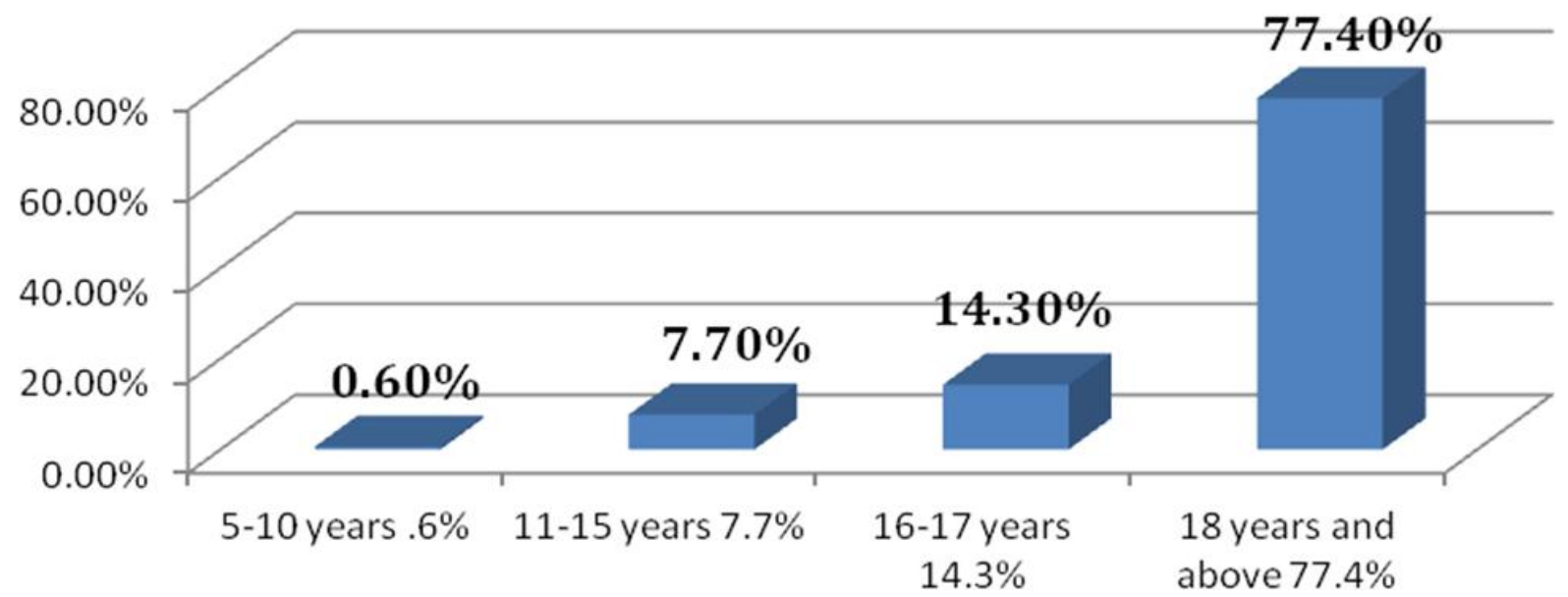

Figure-5.5. Current marriageable age of girls in the area. Own survey 2012 .

Early marriage has been paid due attention by GOs, NGOs, and charitable organizations. It has brought about multi-dimensional problems on women and girls. The former Women Affairs office the current Women, Children, and Youth Office has strived a lot to minimize and further stop it along with other concerned bodies (community policing officers and health extension agents). This has been further assisted by Ethiopia Family Guidance Association. It has employed a focal person in each kebeles with a monthly salary who distribute contraceptive pills to ascertain family planning. Hand in hand, the focal persons work to prevent early marriage, advice parents or guardians not to wed girls early. When girls married early, they (focal persons) distribute contraceptive pills and increase girls' awareness about family planning.

The current prevalence of early marriage is decreasing as a result of the increased awareness and continued effort of the concerned bodies (Women, Children and Youth Office, Health and Education Offices, Justice Office and Police station). The quantitative data (shown on the above graph) of the survey respondents also revealed that girls are most often wedded at the minimum legal marriage age.

Interviewees and FGD participants were asked about the current situation of early marriage. They (interviewees and FGD participants) said that it has vividly reduced in a remarkable manner. This is because there are governmental structures (school teachers, health extension agents, kebele officials, women associations) making serious follow up about who is going to wed his/ her child early. These parents were given advice in advance to stop the wedding process or examine the brides' age by an authorized health center. If, parents were not willing to abort the wedding process they would be legally accused and being punished by the applicable law.

The key informants recognized that there is still a problem of early marriage in the kebeles. Parents examine and certify the elders' age at the health institutions, but wed younger's girls under the cover of those who are at their marriageable age. On the other hand parents conduct all the marriage process and ceremony confidentially but with the pretext that they are preparations for social holydays. In general, though quantitative and qualitative data shown that early marriage had been remarkably decreasing but there is still slight problem in the area which needs great attention.

\subsection{Causes of Early Marriage}

\subsubsection{Findings of the Quantitative Survey}

The main causes of early marriage in the study area were to keep the tradition and norms of the society $19 \%$, to collect dowry (for the sake of financial benefit) $8 \%$, to keep virginity and premarital sex $11 \%$, to see their children marriage ceremony $26 \%$, to bring back their gifts during marriage $19 \%$, to create social bonding (kinship) 16\% (Gozamine Woreda Culture \& Tourism Office, 2004).

Early marriage has caused multifaceted problems on women and girls life. It is perpetuated owing different causes. These causal problems are almost common and are the same which are due to the inequality or subordinate position of women in the society, but are different in degree. Among the influential cause of early marriage are the traditions of the society, using girls as a means to create social bonds, lack of knowledge about its impact on women and the society's expectation of many births from women are identified in the study area.

The survey result in the graph below regarding the causes of early marriage love and deep fonder among couples constitutes 25.4\%; religious hurdles and barriers constitutes 21.7\%; raising economic status by collecting dowry constitutes $62.3 \%$; increasing social/prestige/ status by creating bond with in-laws $71.1 \%$; lack of access to education/ illiteracy $32.3 \%$; increasing of the family size by making girls to give birth early constitutes $83.7 \%$. 


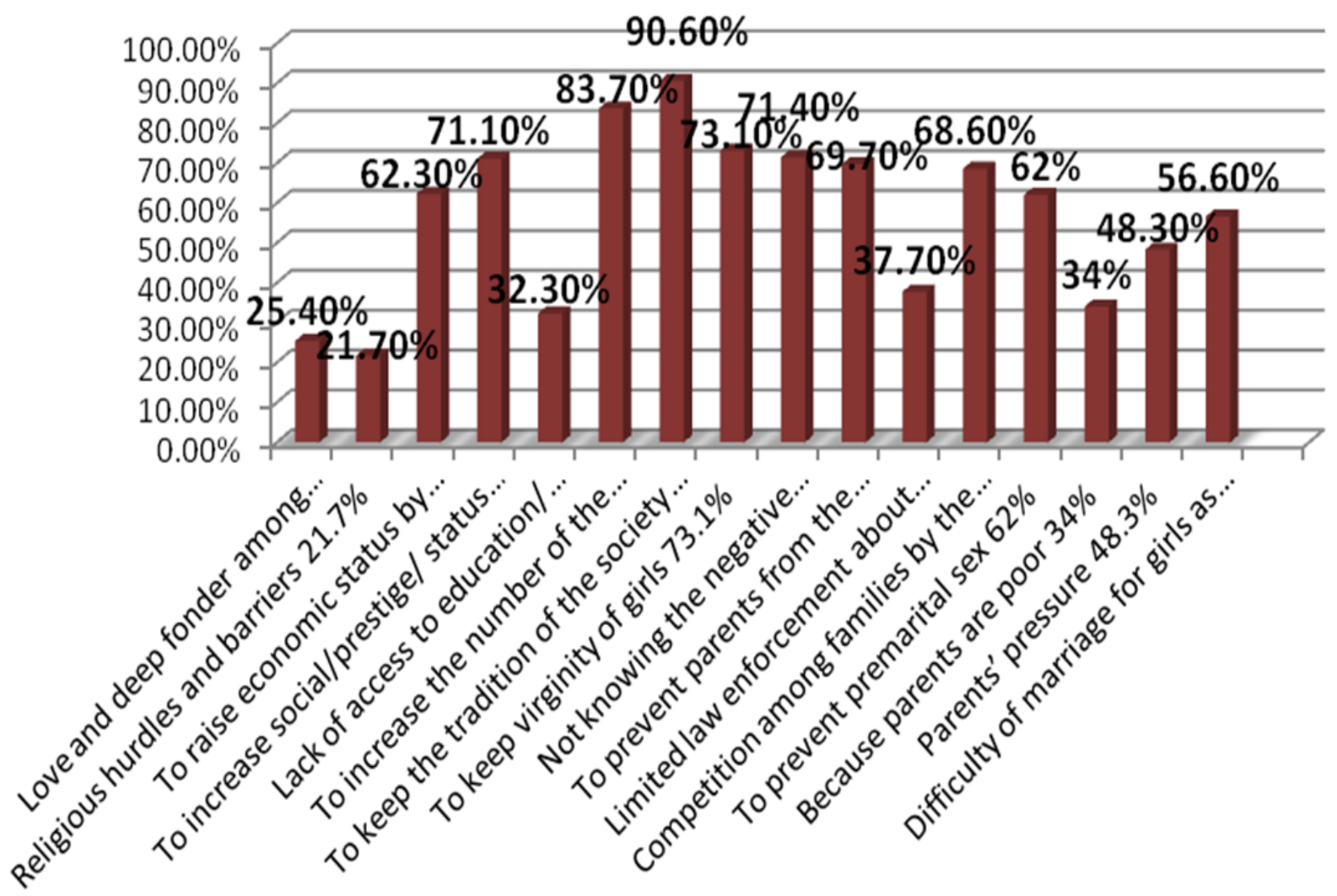

Figure-5.6. Percentage of the causes of early marriage in the study area.

Own survey 2012

Besides keeping the tradition of the society constitutes $90.6 \%$; keeping virginity of girls $73.1 \%$; the society's lack of knowledge about the negative consequence of early marriage $71.4 \%$; preventing parents themselves from the community gossip and innuendo $69.7 \%$, limited law enforcement about early marriage $37.7 \%$; competition among families by the number of children married $68.6 \%$; preventing premarital sex $62 \%$; parents' poverty to fulfill basic necessities for their girl child including education $34 \%$; parents' pressure their girl child to marry off early $48.3 \%$; difficulty of marriage for girls as the age increases $56.6 \%$ are among the identified causes of early marriage.

The qualitative data clearly shows that traditional beliefs and thoughts take the lion's share causal problem for early marriage in the study area. A father who did not wed his girl child is often condemned by the society when he avails himself on others' wedding ceremony. Those who wedded their girl child early insult others who did not wed their girl child early "One who did now know wedding his/her girl child should not avail him/herself at wedding ceremony” /medar yemayawuk yesew deges mabilat man astemarewu/, "she/he who did not wed should not eat" /lijun ayder, aybela yesew degis/. These traditional beliefs go up to the discipline and manure of a girl child including her virginity at the evening of her wedding day. The girl's virginity has a grand value in the study area and gives a great honor to her parent which is a proof for their upbringing and good management. On the other hand if a girl gives birth before marriage, she is highly disgraced and has a lasting impression on her life and her families as well.

These and other insultations discourage parents to educate rather to wed heir girl child. Thus, keeping the tradition of the society; preventing girls from premarital sex; keeping her virginity; competing interest of grandparents to have many grandchildren; creating social bonding or kinship and preventing parents from community innuendo play decisive role to sustain early marriage. However couples good will and love, religious hurdles, education inaccessibility, limited law enforcement had less factor on causing early marriage, even though they have their own contribution on causing it.

\subsubsection{Findings of the Qualitative Survey 5.2.2.1. Keeping the Tradition}

According to interviewees, there is strong social pressure on families to conform marriage. Failure to conform can often result in ridicule, disapproval or family shame. Interviewees and FGD participants reported that a girl who is not married by late adolescence represents a failure and disgrace to the family. In particular, the status of the girl's father is compromised, and faces innuendo by the community when he avail himself at others wedding ceremony. Invariably, local perceptions on the ideal age for marriage, the desire for submissive wives, extended family patterns and other customary requirements, are all enshrined in local customs or 
religious norms.

According to the opinions of the informants, as well as the results of review of relevant literature, the major reported explanations for the approval and actual practice of early marriage include the desire or need to maintain the family's good name and social standing. There is also a personal interest mostly among fathers to create bonds or relationships with families of choice. These customs, combined with a fear that the girl might become unmarriageable later in life and the need to ensure virginity (a show for families good cultivation and grow of their children) of the girls at the time of their first marriage, are the driving causes of early marriage.

Early marriage has a high prevalence rate in the study area, because of deep rooted traditional norms. These associated early marriage with a families' status within the community, as status is closely bound up with the success of children, in most rural communities a daughter's marriage represents her success. There is an old traditional concern that a girl will become too old for marriage, which will represent a failure on the part of her parents. Analysis reveals that what is really sought here is not the satisfaction or well-being of the daughters, but that of the parents. It appears that a man's status in the community is greatly influenced by the success of his children not by educating girls' but, by making them marry early and securing virginity.

In some cases, community members could not imagine marriage beyond younger ages. An older unmarried daughter can become a disgrace to her family, prompting community rejection of the family and victimization of the girl through verbal attacks and gossip that the family simply cannot afford to risk.

However, the most important of the reported reasons for the practice is the traditional thoughts and personal importance of witnessing the marriage of one's children and grandchildren. This is considered as a mark of manhood/fatherhood. The younger generation seem to realize this and regard it as intergenerational issue. That was why adolescents, both males and females in the FGDs and individual interviews were highly emotional when expressing their disapproval of the practice. The fact that traditional and cultural values are the most important causes of early marriage is highly supported by the findings of quantitative data as described below.

\subsubsection{Keeping Virginity, Premarital Sex and Pregnancy}

At her first marriage, a girl is expected to be virgin. If not found virgin during her first intercourse with her first husband, it is a disgrace for her parents and for herself. In this context, the preservation of a girl's virginity until marriage is primarily parents' responsibility. If she is found against, the society undermines the girl and her parents' morally and socially too. The local community blames parents more than the girl for the loss of her virginity.

According to interviewees and FGD participants, virginity can be considered as an image of innocence and is a good respection for the families. In cases where the girl is not virgin on the very day of her first marriage, her husband punishes her with his belt and any other wooden stick till she tells him who has disvirgined her. Even though the groom is unable /incapable/ to take her virginity the groom punishes her with no reason but to show his superiority and power of dominance. Unwanted pregnancy associated with unsafe abortion is getting increased among rural girls living with their parents or guardians due to their unsafe sex and lack of freedom because they are afraid of their parents and guardians to use contraceptive pills.

Even though contraceptive pills are available in kebele health centers, unmarried girls living with their parents and guardians are not in a position to find and use. Because their parents may hear that their daughter has started sex, and on the other hand, in case a girl is not virgin at the date of her marriage, her parents face community gossip and innuendo. Early marriage is greatly influenced by the importance placed on maintaining family honor and the high value placed on a girl's virginity. It is considered that shame would be cast on a family if a girl was not a virgin when she marries. Therefore, in order to ensure that a girl's virtue remains intact, girls may be married earlier, in order to ensure their virginity. This makes girls to marry early in the community.

\subsubsection{Creating Social Bond and in-Laws Kinship}

Marriage is defined as a rite of passage that every individual is expected to undergo in his or her lifetime, and the integral purpose of this institution is to widen the kinship network of the individual through procreation. Also, affinal relatives (relatives by marriage) are acquired in addition to consaguineal kinship (blood relatives). Families are made of a wide network of members, including brothers, sisters, parents, grandparents, uncles, aunts, cousins, in-laws, unborn children, and deceased relatives. The wide network of family members functions as a social unit with norms and beliefs and as an economic unit for the survival of its members.

According to the response of the interviewees and focus group discussants marriage is formed and created by parents (groom and bride families) interest to make kinship. Selected parents of the study area are interested to form marriage with families who are respected (whose voice is publicly heard loud and sound), wealthy (in the size of land and number of cattle owned), and racially respected (who are not weavers, hand craft makers, traditional leather sleeping mat, and etc). More often, families themselves select /engage/ other families for their children to make marriage relation but they do not select the groom or the bride. The 
families' acceptance, their voice to be heard publicly, and their material or property is a vital criterion for the selection of marriage among families. On the other hand, making marriage with a priest is supposed to be good and is holly. Such a marriage is for life and cannot be divorced because it is religiously prohibited which is believed to be sinful.

\subsubsection{Lack of Knowledge}

Most of the rural women and men are not literate enough; hence, they do not know the negative consequences of early marriage well. As a result, they also make their daughters marry early at the age where it is time to go schooling. It may also be thought that parents approve and practice early marriage because they are ignorant of its negative consequences upon their daughters. Families are highly interested to make marriage bond with religious leaders by giving them great respection and thinking that their girl is kept intact with her husband where by marriage is for life. These religious leaders (priests) want to marry virgin girl to keep their holiness. As a result they wants to marry a girl who is not attain the right legal marriage age to assure her virginity.

However, reports from informants reveal that lack of knowledge about the negative impacts can never be explanations for its prevalence in Gozamine Woreda. For instance, two informants (a key informant and a member of one of the ever married women's FGD) mentioned that they knew a number of persons who vehemently disapprove early marriage and/or decry its negative impacts at public gatherings, but they, nevertheless, pursue the practice in their own homes. People in the study area arrange the marriage hidden from neighbors and kebele officials, but make the ceremony under the cover of other social relations (mahiber, senbetie). This shows that they know it is legally prohibited and is punishable, but they do not consider the girl's misery. Thus, parents, community elders and guardians have knowledge gap on the cause and its associated problem.

Moreover, key informants and FGD participants reported that people often disapprove early marriage and even temporarily stop the practice, but some relapse back into the practice sooner or later, due to the strong and deep rooted traditional values attached to the practice. However, the overall trend shows that the practice has been decreasing in recent years, most importantly after the May 2005 revised Criminal Code of the Federal Democratic Republic of Ethiopia and the Revised Family Code proclamation of 2000.

\subsubsection{Poverty/Economic Causes}

Poverty is a critical factor contributing to child marriage and a common reason why parents may encourage a child to marry. Where poverty is acute, a young girl may be regarded as an economic burden and her marriage to a much older sometimes even an elderly man is believed to benefit the child and her family both financially and socially. Some analysts explain early marriage in Ethiopia as a way of improving the economic status of the family, arguing that poverty forces families to wed their daughters at a young age. However, according to the results of the qualitative assessment, poverty is not a major cause of early marriage in the study area, if it is a cause at all.

For one thing, according to the opinions of the FGD participants and key informants, many of those who approve and/or practice it are relatively well-to-do. In this area as it is discussed as a causing factor, it is not for the gain of the brides' families rather to wed the girl who are economically better for the brides' future betterment. This is because no money is paid for the family, the money paid as dowry is for buying clothes and other jewelry. On the other hand the bride's families give traditional leather mat and pillow for the groom where they (the groom and bride) sleep together. Thus, no economic benefit is encountered for the bride's families rather it is mutualism.

W/o Anchinalu Damtie's story

Anchinalu was first married at the age of 10 to the one whose parents were rich in land holding and were respected and powerful in the community. Her parents arranged the marriage with the mediator of community elders thinking that she will inherit land and to create affinal relatives (relatives by marriage) with her in-laws. After the wedding date, her 24 years old husband and his parents do not treat her as a wife rather as a domestic servant. When she was 13, she gave birth for a female child, but her husband and his parents were not happy rather consider her that she is not good at delivery. Hence, they demoralize and over burden her on domestic work. They need her to give birth for male children; unfortunately, she gave birth for four female children.

Consequently her husband along with in-laws divorced her with her children with no property division then he looks for another wife who may give birth to male child. At the time, she had no way to go, and no food for her children. She got employed in rich families to do domestic works like baking injera, cleaning cloths, roasting maize and wheat for traditional alcohol (derekot and abshelo for tella). After a while she married a man whose wife has died leaving seven children. From her new husband, she again gave birth to three children (two male and one female), but her husband died and her step children together with their relatives sent her off by claiming that all the property including the house is their deceased mother's property. Since she cannot feed her seven children, she decided to give them to those who can feed with no additional payment. Now her children have no accessed to education all are illiterate.

Early marriage is causing its lasting impression and all rounded problem on women and girls life. As it can be clearly shown on Anchinalu's life profile, girls have been married even when they are unable to 
distinguish that they were going to marry off. Due to the consensus and negotiation of the in-laws and community elders, she was forced to live with her older husband to meet the predetermined idea which was to inherit land and reinforce the created affinal relativity.

As a result, she gave birth when she was unable to bear and rear her children at the age of 13 which was her time to educate with her age peers. Due to this reason she cannot join schooling and hence, lagged behind standing her rights of getting access to her properties. Her parents and community elders who mediated the marriage did not stand beside her when she had no chance to feed and met basic needs to her children. Anchinalu started working daily labor work for wealthy families to feed her children. This all influence is created as a result of early marriage on girls and women.

Moreover, for most families there is no significant economic benefit to be realized from early marriage of their daughters. In accordance of few informants the desire to get macha (money that the groom's family gives to the bride's family based up on the agreement of the marriage) was mentioned as a possible motive.

\subsection{Consequences of Early Marriage}

\subsubsection{Findings of the Quantitative Data}

Early marriage creates a problem on the social-economic and health condition of women. An analysis of several indicators from the 2005 Demographic and Health Survey (DHS) in Ethiopia shows that marital status greatly influences the sexual experiences and reproductive health of girls and young women in Ethiopia. Married girls are significantly more likely than their unmarried peers to be sexually active (73 percent versus 0.3 percent) and because of tremendous social pressure for them to prove their fertility, these young brides become young mothers with the attendant dangers of early childbearing.

The main problems that would be encountered on women due to early marriage in the study area are school dropout constitutes $25 \%$, presence of many children constitutes $23 \%$, early pregnancy constitutes $17 \%$, poor parental caring and bearing of children constitutes $14 \%$, abortion constitutes $10 \%$, maternal mortality $5 \%$, prolonged labor $4 \%$ are the main consequences of early marriage in the study area (Gozamine Woreda Culture \& Tourism Office, 2004).

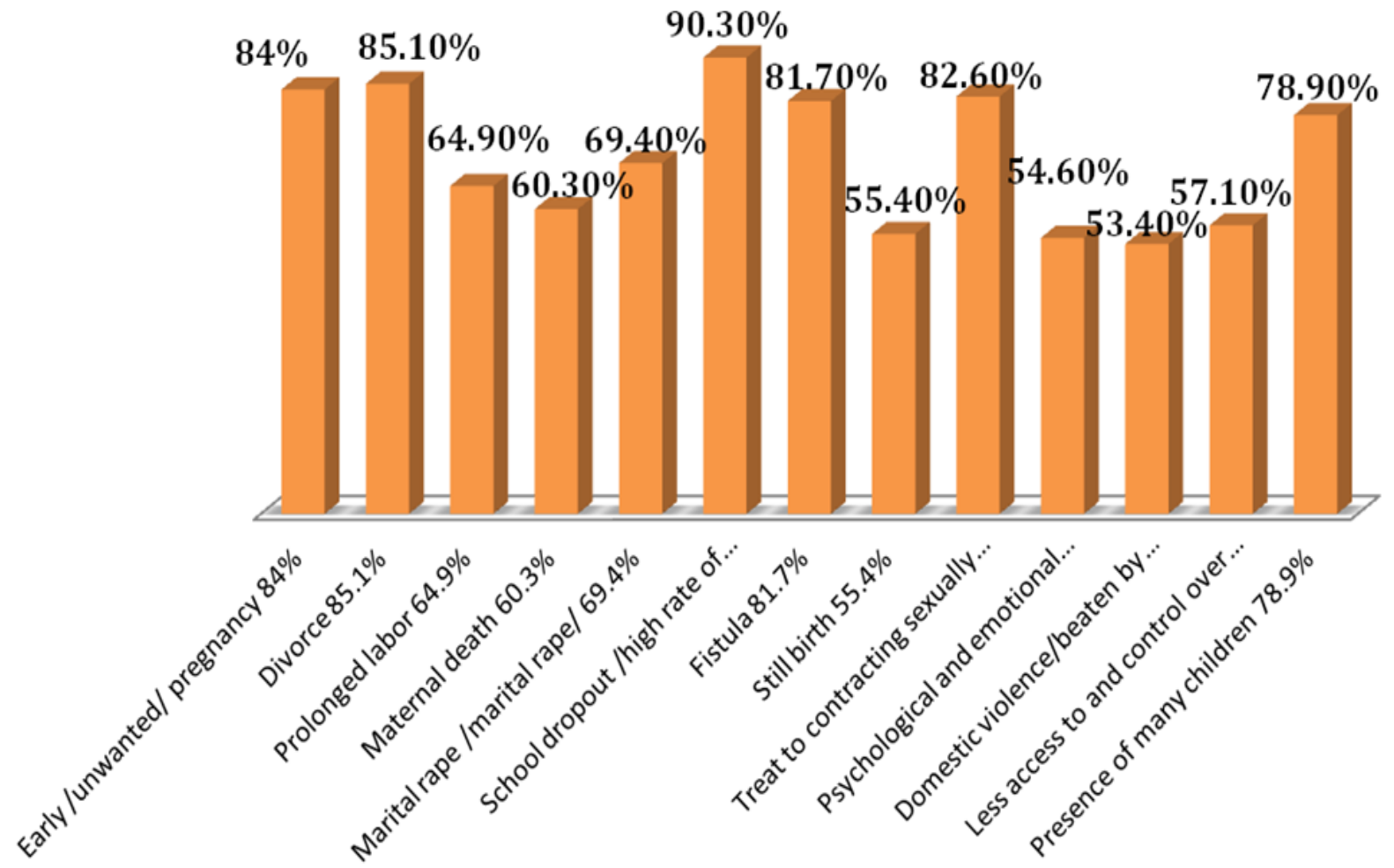

Figure-5.7. the percentage of the impacts of early marriage on women and girls. Own survey 2012

In areas where early marriage is prevalent, it has multi-dimensional consequence on the health and socioeconomic of women as well as girls autonomy and self-esteem. As shown on the above graph, girls' school dropout due to early marriage accounts $90.3 \%$, divorce accounts $85.1 \%$ associated with repeated marriage, early / unwanted/ pregnancy accounts $84 \%$, and followed by health associated problem (Fistula $81.7 \%$ and Sexually Transmitted Diseases including HIV/AIDS Accounts 82.6\%).

Moreover, there are other associated problems which bring about different problems on women such as during delivery. This results in the occurrence of prolonged labor which account $64.9 \%$, maternal mortality 
accounts $60.3 \%$, marital rape accounts $69.4 \%$, psychological problem contributes $53.6 \%$, and $53.4 \%$ of the respondents said they face domestic violence. This shows that early marriage is influencing the health condition and socio-economic aspects women.

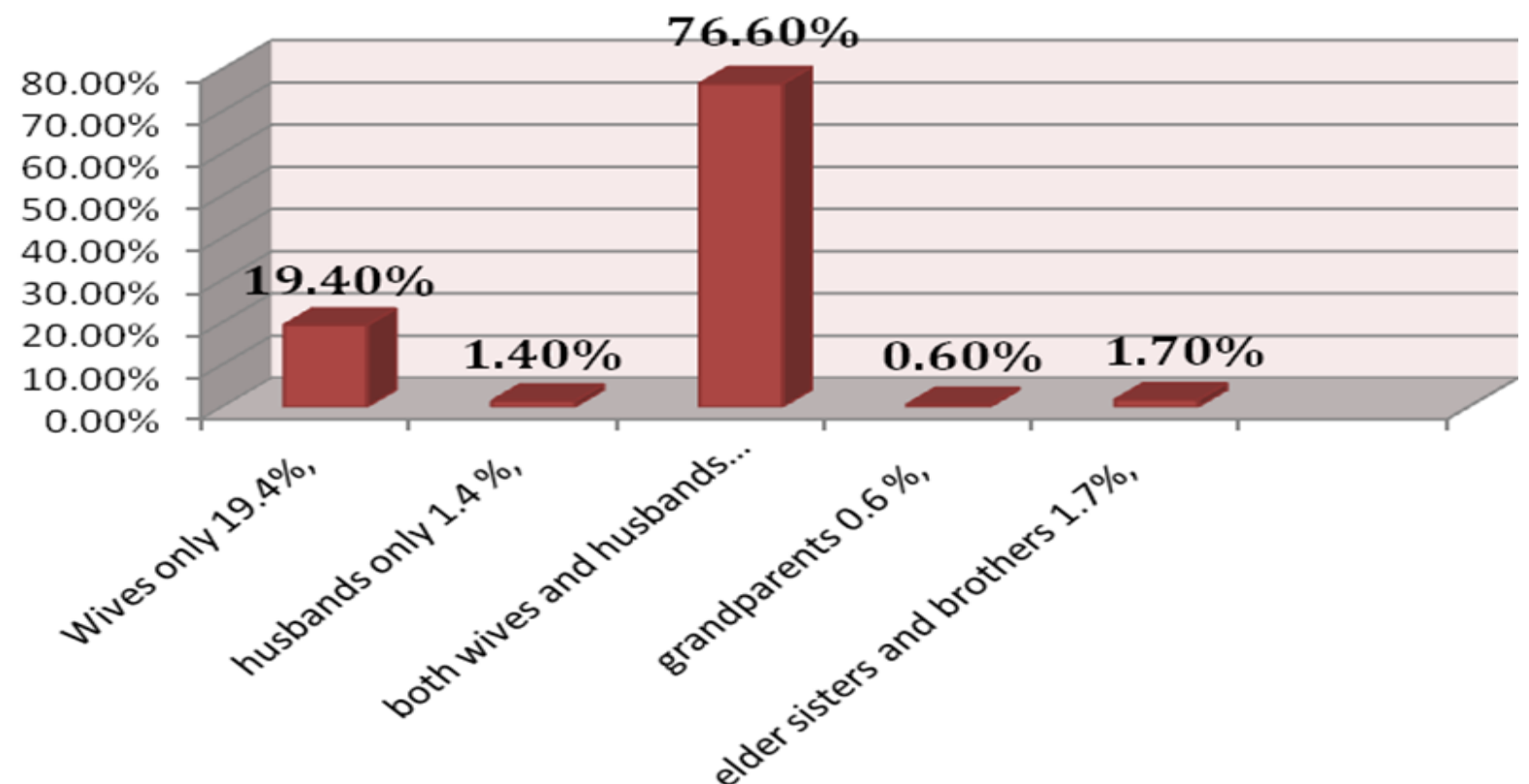

Figure-5.8. The percentage of the responsibility of couples in rearing and bearing children. Own survey 2012

Early marriage increases women's domestic violence and made them work longer hour due to the societal gender role classification. Early married women do not develop self-confidence; do not negotiate for safer sex, unable to freely decide to use contraceptive pills, and longer working hour including bearing and rearing children. Quantitative data obtained from the survey respondents showed that women are more likely rear and bear children. The survey data shows that, child bearing and rearing is the responsibility of wives constitute $19.4 \%$; about $1.4 \%$ responded that it is the husbands responsibility; $76.9 \%$ it is the responsibility for both wives and husbands; $0.6 \%$ of the respondents said that it is the responsibility for grandparents; and $1.7 \%$ of the respondents responded that rearing and bearing children is the responsibility of elder sisters and brothers.

Early marriage influenced on women decision making power. Because as women married older husband, they lack the opportunity to discuss on common matters. As a result they are considered as unable to made concrete, reasonable and wise decision owing to their younger age. Thus those wives who are expected to made such unwise decision have no voice to be heard. As the data obtained from ever married women showed that about $10.6 \%$ of the decision made by wives alone, husbands decide alone $14.5 \%$ on common properties, $74.6 \%$ of the decision on common properties is made by both wives and husbands through discussion, and about $0.3 \%$ of the decision on spouses common property was made by in-laws.

The result obtained from the survey respondents (10.6\%) women super decision making power is due to the absence of husbands. More often wives decide on common properties whenever they are divorced, or living alone, widowed, and their husbands are disabled. Though the quantitative result showed remarkable data, this power is limited on the absence of their husbands.

\subsubsection{Findings of the Qualitative Data}

As key informants said and FGD participants confirmed that rearing and bearing children is most often the business of wives. The responsibility of husbands is limited on buying clothes and fulfilling educational materials as they have the power to control over resources. Other than this all responsibilities (such as cleaning clothes, preparing food, serving water, taking care for children, and etc) are all that women shouldered.

Open ended questions were employed through the qualitative assessment process to supplement and further explain the consequences of early marriage in the gozamine woreda. According to the findings of this study, early marriage is now well recognized as causing diverse, complex, and interrelated socio-economic, political, psychological, and physiological (reproductive health) problems for young girls.

\subsubsection{Early Marriage on Girls' Educational Attainment}

Higher levels of education tend to be associated with later marriage in Ethiopia in general and in Amhara region in particular. Likewise, opportunity to reach higher levels of education may be affected by traditionally 
appropriate marriage patterns. When a girl lack the opportunity to pursue her education the only option she had is to get married at which her hope to educate disappointed once and for all.

Data obtained from the FGD and interviews showed that early marriage made girls discontinue their education and not to enroll when they got married at earlier age and are expected to marry early by their parents. The availability of opportunities to further her education as well as the willingness of her spouse and in-laws to make it possible to do so is usually non-existent. Ignoring the impact of early marriage on girls' educational attainment has serious repercussions for the future of girls, parents and countries as well where it is a common practice.

The quantitative data revealed that early marriage seriously hampers girls' education. Especially because early marriage is so strongly associated with early childbearing and care of children, for which the responsibility is only hers; a girl's opportunities to access training and education is severely limited if she becomes a wife and mother at an early age.

\subsubsection{Marriage Instability}

According to the 1990 National Family and Fertility Survey 45\% of first marriages in Ethiopia end in divorce within 30 years, and two-thirds of women who divorce do so within the first 5 years of marriage. The Amhara Region is characterized by a very high incidence of divorce. It also seems to be the major origin of the commercial sex workers throughout the country, and both can often be attributed to the exceptionally high prevalence of early marriage in the region. A major negative consequence of early marriage is instability, (disagreements and eventual divorce or separation). Marriage without consent is widely thought to be the major cause for most of the divorces, and many of the early marriages are conducted without the consent of the girls.

Early marriage hinders young married girls from reaching their full human potential, participating in and benefiting equitably from economic activities and decision-making in the communities of which they are a part. Furthermore, very young married girls are not well-prepared to handle household management burdens and child-care responsibilities. Above all, early and loveless marriages usually end in early divorce. Divorced young girls usually migrate to the nearby urban centers and end in becoming domestic servants or prostitutes, which exposes them to sexually transmitted diseases, including HIV/AIDS. In this context, early marriage perpetuates women's subordinate status in society in terms of their lack of access to education, economic opportunity and health.

\subsubsection{Impacts on the Health of the Women}

Reproductive health problems related to early marriage reveal the socio-economic dimensions of young girls' life that are victims of early pregnancy and multiple births. More specifically, health problems related to early pregnancy and multiple births interfere with their opportunities to education, the source of their personal as well as social development and destroy girls and women's ability to fulfill an active economic and socio-political role and to develop their sense of worth. Health consequences of early marriage are early pregnancy complications leading to obstetric 'fistula'. Fistula victim young girls are usually abandoned by their husband, become social outcasts from their community, and vulnerable to social sufferings and abject poverty.

\subsubsection{Early Pregnancy and Maternal Mortality, Fistula and HIV/AIDS Infection}

An estimated 16 million girls aged between 15 and 19 give birth every year, with $95 \%$ of these births occurring in developing countries. Worldwide, just seven countries account for half of all adolescent births: Ethiopia is one of these seven. In the poorest countries, young motherhood often becomes a death sentence. An estimated 70,000 girls aged 15 to 19 die each year during pregnancy and childbirth and more than 1 million infants born to adolescent girls die before their first birthday.

Compared with women of over 20 years of age, girls 10-14 years of age are 5-7 times more likely to die from childbirth, and girls 15-19 years of age are twice as likely to die from child birth. In addition to jeopardizing the life of the mother, early pregnancy has major health implications for her child. Infants born to mothers under the age of 20 have a $73 \%$ higher mortality rate than infants born to older mothers. In Ethiopia early pregnancy most frequently stems from early marriage, but also from forced sexual encounters; poverty and desperation resulting in transactional sex; lack of awareness about sexual and reproductive health; and/or from a lack of sexual bargaining power preventing contraceptive use. $10.5 \%$ of women not using contraception were not doing so because their partner was opposed, whilst $11.9 \%$ did not use it because of religion. $5 \%$ failed to use contraception because they lacked awareness of the various methods or sources.

Early sexual intercourse, resulting from child marriage is strongly associated with early pregnancy and no contraceptive use, increasing the likelihood of exposure to STIs including HIV/AIDS. In Ethiopia, a national survey on the effects of harmful traditional practices found that $42 \%$ of problems at delivery occur as a result of child marriage and early sexual initiation. Pregnancy at an early age often leads to obstetric fistulae and permanent incontinence. 


\section{Fistula and Related Problems}

Amhara region, Fistula severely exists compared to other regions. Of women coming from all regions for care at the Addis Ababa fistula hospital, 40\% were from the Amhara Region. The only fistula hospital/service in Bahr Dar town, capital of the Amhara Region, has reached its capacity to deal with the problem (Pathfinderr International/Ethiopia, 2006). Prolonged and obstructed labor in most cases results in obstetric fistulas. It is important here to remember that problems with fistula are generally kept secret and rarely publicized; only those who are very close to the concerned individual know about it. Hence, the magnitude of the problem is most probably higher than what is reported here.

\section{HIV/AIDS Infection}

Married girls have higher levels of sexual activity than their sexually active unmarried peers, have limited ability to negotiate condom usage and have low power to refuse sex from their partner. Additional health risks are brought upon married girls by the pressure on them to become pregnant.

The HIV/AIDS pandemic has highlighted the role that gender inequalities and inequities play in the spread of the infection. However, the effects on early marriage and the individual livelihoods of married adolescent girls have hardly been addressed in any literature. Recent epidemiological data confirms that young women are being infected at a higher rate than men, especially in sub-Saharan Africa. Among the two-thirds of newly infected, 15-19-year-olds in the region are female. Being young and female in parts of Africa seems to be a major risk factor in becoming infected or affected by the HIV pandemic. In the early days of the HIV epidemic, heterosexual relationships were considered safe and, as such, early marriage may even have been encouraged as a safe haven for a number of girls now living with the virus. However, the low decision-making powers and limited economic autonomy of many married girls will further increase their vulnerability to HIV.

Tachawute Asheber's story

Tachawute is now a 36 years old woman living in Kebi kebele. When she was at the age of 12, she married a man who was 26 years old with 14 years of age difference. She did not enroll at school while rearing her parent's animals which were many in number. At the very beginning, the community elders arranged the marriage along with her parents' goodwill without asking her consent. Till the last occasion she did not know that she was going to marry, but knew only at the eve of her wedding date. On the night of her wedding day she lost her virginity forcefully. Though she did not want to stay with her older husband and came back to her parents' home, her parents bring her back repeatedly to live with her husband. On the next year, at the age of 13, she gave birth for a male baby.

Tachawute's older husband was a drunker, beats her frequently, and sells common property. During the period, she did not know that whether there were contraceptive pills or not, so she gave birth for her second child. By the time, she had no power to ask why rather this might increase abuse and violence by the husband; he could do all what he preferred. When the violence was increased from time to time she left back all her property and children and went to a city where she was employed as a waitress in a bar. During her 10 years of stay in city as a waitress, she got her self HIV/AIDS positive. Now, she returned to home country and living with her older families. In Kebi the communities including her parents had low awareness about the HIV/AIDS. As a result, she was facing stigma and discrimination.

Tachawite's story shows that girls in rural areas have been facing violence publicly and /or domestically. The community was very much interested to wed girls rather than sending to school. At their earlier stage, while they are not resistant to their families' opinions parents arrange the marriage. Rather they /brides/ are shiny and submissive to their families and elders. Even the girl did not ask and knew that she was going to marry. The bride's parents/guardians considered it as norm. They believe that she was facing violence and abuse by the husband so as to shape and make her perfect wife who is responsible for her house and children. Unless he punishes and violates her right, they consider that he did not want to live with her because he is not shaping her to make a good wife.

As the violence was getting higher and higher by the husband, rural girls prefer to other areas which they did not know, yet living behind their common property even their cloth. The husband and in-laws consider and spoke gossip that she went away to find another male in a city and not to be criticized by the society which is a disgrace to her parents. Due to this reason, the parents did not find and bring their missed child back and did not request for her property. Thus, girls face another intolerable challenge in a city. "Worse is better than the worst". Hence, they became commercial sex workers. This expresses them to became HIV/AIDS positive.

\subsubsection{Increased Number of Children}

Parents make their girl to marry early so as to have many grandchildren. The women's status within the community is determined by the degree to which she meets some culturally defined concept of fertility. In some cases, this definition may be a function of the number of children she bears; in others it may relate to the sex of the children or the age at which she first become pregnant (WHO, 2000a).

Interviewees and focus group discussants said that when the girls marry at an early age, their reproductive life span would increase, and by which they are more likely to have a greater number of children. Due to age differences, economic dependency, lack of education, and many other associated factors, earlymarried women exercise lower sexual and reproductive rights than those who marry at appropriate ages. They have less ability to make decisions on matters related to reproductive health, such as the use of contraceptives 
and rights over sexuality (the ability to say "No" when asked for sex by husbands). Thus, early marrying women have less chance of spacing time between children and/or preventing unwanted pregnancy.

\section{Conclusion and Recommendation \\ 6.1. Conclusion}

In the Amhara region, particularly in Eastern and Western Gojjam, early marriage is a common traditional practice. Different researches showed that even a girl as young as seven is forced to marry traditionally. The determination of such early marriages was arranged by parents $58.3 \%$, relatives $10.6 \%$, community elders $23.4 \%$, self-motivated only $5.7 \%$, and about $2 \%$ of the respondents which is seven in numbers do not know who do arranged their marriage. The input data were collected using area cluster sampling technique covering three kebeles, purposive sampling, and random sampling technique. A total of 350 married women aged 15-50 years were interviewed, using a structured questionnaire. FGDs (three groups having a number of 30 participants) and key informant interviews were also conducted to gather qualitative information on the prevalence, causes and problems associated to early marriage in the study area.

Findings of this survey study indicate that early marriage was highly prevalent in the Gozamin woreda. Among the respondents about $3.71 \%$ were first married under the age of 5-10 years, $55.71 \%$ were first married under the age of 11-15 years, $31.43 \%$ were first married under the age of $16-17$, and $9.14 \%$ were first married under the age of $18-25$. About $61.4 \%$ of the respondents were not asked for their full consent during their first marriage, $22.6 \%$ were asked (but only $35 \%$ were agreed and $65 \%$ were disagreed up on their marriage), and $16 \%$ did not remember whether they were asked or not.

Marriage union in the earlier age is difficult for both couples but the problem is severe for girls and got more sever when they got married who they do not know. Among the total respondents, only $11.7 \%$ (34 respondents) of married girls know their husband both facially and by name before their union, where as $14.3 \%$ knew their husband only facially, $9.7 \%$ knew their husband only by name, and $64.3 \%$ knew their husband neither facially nor by name. The legal background of respondents concerning early marriage had shown that about $85.4 \%$ of ever married women respondents know the legal age at first marriage $(2.5 \%$ said that it is 12 years and above, $17 \%$ said that it is 16 years and above, $80.2 \%$ said that it is 18 years and above, and $0.3 \%$ said that it is 25 years and above), and $14.6 \%$ did not know the legal age at first marriage.

The main reasons for early marriage in the study area (in this case Gozamine Woreda) included a combination of socio-economic and traditional factors. These include: love and deep fonder, among couples (25.4\%), religious hurdles and barriers constitutes $21.7 \%$, to raise economic status of girls' families by collecting dowry constitutes $62.3 \%$, to increase social status /prestige/ by creating bond with in-laws constitutes $71.1 \%$, lack of access to education/ illiteracy of girls parents constitutes $32.3 \%$, to increase the number of the family by making girls to give birth early or to let the family chain continue constitutes $83.7 \%$, to keep the tradition and norm of the society parents or guardians live with constitutes $90.6 \%$, to keep the virginity of girls constitutes $73.1 \%$, parents not knowing the negative consequence of early marriage constitutes $71.4 \%$, to prevent parents themselves from the community gossip and innuendo constitutes $69.7 \%$, limited law enforcement about early marriage constitutes $37.7 \%$, competition among families by the number of children they wedded which is a show for families status on the community constitutes $68.6 \%$, to prevent premarital sex constitutes $62 \%$, parents poor economic status to feed and meet basic needs for the children constitutes $34 \%$, parents' pressure to wed their girl child constitutes $48.3 \%$, difficulty of marriage for girls as the age increases ("Qoma Qerech") constitutes $56.6 \%$ are the main indentified causes of early marriage in Gozamine woreda.

The main consequences of early marriage in the study area are multifaceted and different such as early / unwanted/ pregnancy-84\%, increase divorce rate- $85.1 \%$, prolonged labor during delivery- $64.9 \%$, maternal death-60.3\%, marital rape /marital rape/-69.4\%, school dropout of girls and not getting enrolled in schools from the very beginning / high rate of illiteracy-90.3\%, fistula- $81.7 \%$, still birth of children-55.4\%, treated to contracting sexually transmitted disease such as HIV/AIDS-82.6\%, psychological and emotional stress/forced sexual relations, denial of freedom, and personal development as house hold chores $/-54.6 \%$, domestic violence like beaten by husbands, caring and bearing children with no the aid of her husband-53.4\%, less access to and control over resources such as land, animals, cash etc-57.1\%, and Presence of many children-78.9\% are identified the main problems associated with early marriage.

The results of this comprehensive survey confirmed that there are different reasons worth mentioning for the prevalence of early marriage in Gozamine woreda and there are untouched areas which need to be researched such as women's decision making power on domestic and public spheres, women's use and control over resources, how to develop their self-confidence, why do women work longer hour, and how women could get good recognition and respect by changing the existing gender imbalance. The findings of this study showed that about $2.9 \%$ of the survey respondents started sex below the age of $10 ; 67.1 \%$ from $11-17$ years of age; $30 \%$ from 18 years of and after. Among the respondents those who have children about $38 \%$ of the respondents give their first birth within the age $12-16 ; 36.9 \%$ of the respondents within the age of $17-18$; $22.6 \%$ of the respondents within the age of $19-25 ; 1.4 \%$ of the respondents at the age of 26 and above; and $1.1 \%$ of the respondents did not know at what age they gave their first birth. 
Rural married women have great challenges on deciding on common properties, responsibility on caring and rearing children. This is because they married whom they did not know before marriage and were older than them. For instance about $43.4 \%$ of the respondents married a husband who was older by $1-5$ years; $38.6 \%$ married older than the wife by $6-10$ years of age; and $18 \%$ wives younger than them by 10 years. About $19.4 \%$ of the respondents aforementioned that the responsibility to rear and bear children is the wives responsibility, $1.4 \%$ the husband only, $76.9 \%$ mentioned that it is responsibility of both the wife and the husband, $0.6 \%$ mentioned that it is the grandparents responsibility, and $1.7 \%$ reported that it is the responsibility of elder sisters and brothers. Concerning on the decision on common property about $10.6 \%$ of the respondents reported that wives alone on common properties, $14.5 \%$ said husbands alone, $74.6 \%$ said that both wives and husbands together, and $0.3 \%$ said that the responsibility should be for both.

\subsection{Recommendations}

Early marriage is recognized as violation of human rights, consequences multifaceted problem on health, economics and social affairs on girls and women, and also inhibits young girls from attaining education that would have a lasting impression on their life and well-being. Based on the findings of the study, the following recommendations are forwarded to help reduce and ultimately eliminate the practice of early marriage and lessen the misery of thousands of girls in the study area.

\subsubsection{Address Traditional Values and Norms}

The study findings indicate that traditional values and norms play a decisive role on early marriage. As child marriage is a tradition that has been deep rooted in the society. Parents may be unaware of the dangers, or may feel that it is a show for their economic status, to have good name in the society, to be competitive, and to prevent themselves from community innuendo and gossip. Even where parents and children understand the negative outcomes of early marriage, societal pressure and the tradition they live in force them to conform to the marriage. The societal poor understanding and beliefs as well as traditions promoting early marriage need to be challenged.

\subsubsection{Empower Youth}

Youth Empowerment (building the capacity of youth associations) by providing youths different trainings and enabling them to participate in conferences and community conversations make them equipped and aware about the negative consequences of early marriage. If the youth are well-fed they can convince family and community members that early marriage greatly affects all the community members in general and women and girls in particular, and create sensitization forums for community leaders such as woreda council members, kebele women and youth association members. Giving due focus for school clubs is also essential as they are the first harmed institutions by the practice. It is important to establish anti-early marriage clubs and strengthening the girls club at every school plays a decisive role on minimizing and handling early marriage.

\subsubsection{Empowering Community-Based Organizations and Community-Support Organizations}

(such as religious institutions and social associations such as idir, ekub, mahiber, and confessor-fathers as well and any other local civic organizations), and governmental structures have also nonreturnable role. Government structures serving as a pillar by coordinating and mobilizing social associations to minimize control and eradicate this severe harmful traditional practice. To convey message and to get acceptance using these community-support organizations is important. This is because in rural societies, these organizations have unreserved power to govern the members of the organizations as religious commandments have a great respect. Thus, one who missed and does not respect the rules and obligations of any community organization can be punished by the community by-law. It may reach up to membership dismissal and isolation from any social life. Hence, these community-support organizations should continue to serve as the means to raise awareness about the negative impacts of the practice and have to be supported, organized and reinforced in line with governmental organizations.

\subsubsection{Give Training to Health Extension Workers and Elementary School Teachers}

Increase the capacity and widen the knowledge of health extension workers, Community-Based Reproductive Health Agents and school teachers of the rural kebeles by providing additional training to enhance their knowledge and teaching on consequences of early marriage and existing laws and policies, so that they can raise the awareness of community members in these areas. The health extension workers in all rural kebeles are women who have access to the more exposed groups. The exposed groups of women are free to speak out what they feel and burden they carry for women.

On the other hand, to extract and address the violence attributed to early marriage; it is important to be systematic and get trust and acceptance. To do so, health extension workers and school teachers have to be systematic to know the problem deeply and address the problem. Moreover these civil servants have the access to get massive population of their kebele to convey message. For instance teachers and health extension 
workers can convey message and teach the society to raise awareness at parents' day, Sunday at church community meetings, field visit, vaccination day, anywhere they can get members of the community.

\subsubsection{Increase Law Awareness of the Society}

Early marriage is not a concern of only a single sector. It laid its hand on every body's life. This is because most of the society understands that the punishment resulting from violating the law on early marriage is low. Some FGD participants said that parents believe nobody is concerned about my daughter whether I marry her off to a husband early or not. Some said that they do not know that early marriage is punishable by the applicable law. Thus, Culture and Tourism Office, Women, Children and Youth Office, Education Office, Health office should work in collaboration with police station and justice office to give training and awareness raising trainings to rural people in general and women in particular and make it clear that early marriage is a major violation of the rights of children.

There is a good start in the study area of some kebeles that, kebele officials arrange a programme and inform police station, and justice offices to give training on "what the law says about early marriage". But it is not well functioning on every kebeles, it only depends up on the strength of the kebele officials. Hence, it should be scaled up covering the whole kebeles to address early marriage as a problem. Despite the fact that it is a multifaceted problem it could and would not be covered by any single institution, rather all should stand against it. As a result, all the above illustrated offices, any charitable organizations and NGOs should work to raise the legal awareness of the society at large. Eventually, Strengthening law enforcement bodies to enable them to effectively discharge their duties and responsibilities, with due attention to the implementation of the family law and respect for children's rights.

\subsubsection{Support Partners against Early Marriage}

Community organizations that oppose early marriage, such as Women’s Organizations, Women's League, and Youth Associations need support need reinforcement to ensure that they have the capacity to act effectively as advocates against it. They should work jointly with religious leaders, NGOs, charitable organizations, and GOs such as Health, Justice, Culture and Tourism, Women, Children and Youth, Government Communication, Micro and Small Enterprises, Agriculture, Land Use and Administration, Sport and Education offices to develop skill, information and education accessing strategy about the negative effects (social, economic, health, etc) of early marriage.

\subsubsection{Providing Economic Opportunities to Young Girls}

Poverty is one of the causal factors underpinning early marriage. Improving a family's economic status may play a role in reducing child marriage. Reducing poverty in the long term and, more immediately, providing economic opportunities for unmarried girls after they finish school. A girl's ability to earn income can help alleviate family poverty and provide girls, as well as their families, with the option to delay marriage.

Efforts to improve the access of young married and unmarried girls to economic resources should focus on expanding employment and entrepreneurial opportunities. Micro-credit programs should better provide women and girls with the basic economic opportunities. They often lack a social support network that promotes changes in attitudes and behavior. It serves as a means of granting them higher status and more control over their lives including their preference in marriage (Kabeer, 2005; Umashankar, 2006).

\subsubsection{Promote Girls Education}

The findings of the study showed that early marriage is a series problem for girls' school dropout and not to get enrolled at the very beginning. Educating girls could and would be the ideal solution for girls not to marry early. Since, if efficiently prolonged and continued to higher level, it helps to delay marrying early, and confers other benefits as well. However, sending children to school costs money and where money is scarce, it is unlikely invest much on girls. Even where education is highly subsidized or even free, poor parents have to pay for some of the costs of school attendance for their children, such as various fees, books, school uniforms, dormitory rent, and food. Mainly higher secondary schools are located in cities and sub-cities. But, in rare case it could be found in clustered kebeles which encompass and mediate five or six and above kebeles. However, forwarding advice to parents to send their girl child to school when schools are too far will not work. Making schooling for girls more accessible is very important.

Education in cities and sub-cities has additional costs which could be incurred for education and transportation as well. Thus parents do believe that girls living in cities become disgrace and start sexual relation than paying attention to their education. As a result of those girls who got the chance to start primary education are likely to drop out of school when they join junior schools. In this case, governments, NGOs and other charitable organizations should create conducive atmosphere for girls to encourage them to educate and convince parents. Such as providing financial support for girls who are going to drop out due to lack of assistance, furnish part time education to strengthen girls, and other material support for girls' education such as free books, uniforms, scholarship and so on. 


\subsubsection{Use Mass Media to Raise the Society Awareness}

Mass Medias have significant role to increase the awareness of the whole community about the consequences of early marriage on girls themselves, their family, on the community as a whole and on the country economy at large. Mass Medias can address massive population within a short period of time. As a result Medias help to insure the domestic applicability of the national, as well as international legal instruments already ratified about girl's human rights. Once communities are sensitized, and trusted on the ideas that they herd or red on accessible Medias, the parents sent their girls to school voluntarily and support them to stay on. In rural areas the trend for using mass media is limited but some respondents said that they do have access to radio message and few of them were accessed to newspapers. Message conveyed through mass media especially on radio leads to the empowerment of girls into skills for self-confidence, assertiveness, speaking out, decision-making and negotiation.

\subsubsection{Gender Budgeting and Gender Auditing}

Governmental and non-governmental organizations should exert a huge effort and allocate remarkable amount of budget for gender mainstreaming in which early marriage is incorporated as a main issue as it is the rote cause of all means of women operation. Different offices should allocate a certain amount (mostly $2 \%$ of the annual budget of offices is considered as gender budget) budget to work on gender equality. This gender budget would serve to empower women and gender planning to fill the existing gender gap. This further helps to minimize and control early marriage at large. To ascertain that this gender budget is serving for its predetermined goal gender auditing should be launched effectively.

\subsubsection{Conduct Further Research on Early Marriage}

In developing countries the issue of early marriage is a question of lively hood. Though it is a burning issue and is a problem of everybody researches are not well done in areas where the problem is magnificently prevalent. The research on child marriage is still relatively new in developing countries, and several issues demand further study such as its prevalence (age gap between couples, first marriageable age, legal awareness of the people), the main causal problems of early marriage in a certain area, and what the consequences are on the economic, social, psychological, physiological, and on the health of both sexes. Interventions also can support efforts that postpone marriage, such as education and employment; women are more likely to marry men closer to their own age when they postpone marriage.

\section{References}

Angela, H. (2001). Early marriage child spouses; UNICEF innocent research center Florence Italy.

Bogalech, A. (2006). Early marriage in Ethiopia: Causes and health consequences, AA Ethiopia.

Central Statistics Authority. (1993). The 1990 national family and fertility survey report. Transitional Government of Ethiopia, Population Analysis and Studies Center, Addis Ababa.

Erica Field. (2004). Consequences of early marriage for women in Bangladesh; Harvard University.

Ethiopia Demographic \& Health Survey. (2005). Preliminary Report. Central Statistical Agency Addis Ababa, Ethiopia.

Ethiopia Demographic Profile Prediction. (2012). CIA world fact book.

Gozamine Woreda Culture \& Tourism Office. (2004). The prevalence of HTPs in gozamine Woreda; Debre Markos Ethiopia.

Integrated Family Health Program. (2009). Gender, harmful traditional practices and gender based violence. Prepared for Training of Trainer Unpublished.

International Center for Research on Women (ICRW). (2006). Child marriage and poverty, from too young to wed: Advocacy toolkit: Education \& change toward ending child marriage. ICRW: Washington, D.C.

International Planned Parenthood Foundation, I. t. U. (2006). Ending child a guide for global policy action London: IPPF and UNFPA.

IPPF, E. (2006). Sexuality Education in Europe: a reference guide to policies and practices. Brussels: Wendy Knerr. Disponivel em http://www. ippfen. org/Resources/Publications.

Kabeer, N. (2005). Is microfinance a magic bullet for women's empowerment? Analysis of findings from South Asia. Economic and Political Weekly. Retrieved from http://www.epw.org.in/showIndex.php.

Lewis, I. (2006). Early marriage and education, EENET newsletter. Marriage; a guide for global policy action. IPPF and UNFPA: London.

Margaret, O. (2012). The hidden lives of child widows. London: Open Democracy Ltd.

Max-Planck-Gesellschaft. (2010). Downside of marriage for women; the greater a wife's age gap from her husband, the lower her life expectancy. Science Daily. Retrieved from http://www.sciencedaily.com 7 /releases/2010/05/100512062631.htm. [Accessed April 20, 2012].

Mekonnon, W. (1986). Marriage practice among the Muslims of Dessie; Addis Ababa Ethiopia.

Naana, O.-O., \& Sonita, P. (2003). Early marriage and poverty exploring links for policy and program development; London.

National Committee on Traditional Practices of Ethiopia. (2003). Ethiopian traditional harmful practices: Old beyond imaginings. Addiss Ababa.

National Committee on Traditional Practices of Ethiopia (NTCPE). (1998). Baseline survey on harmful traditional practices on Ethiopia. Addis Ababa, Ethiopia: UNICEF.

Pankhurst, R. (1990). A social history of Ethiopia. Addis Ababa University. 
Pathfinder International/Ethiopia. (2007). Women empowerment in Ethiopia, new solutions to ancient problems. Addiss Ababa: Ethiopia.

Pathfinderr International/Ethiopia. (2006). Report on causes and consequences of early marriage policy and program development, London. Practice: A Statistical Exploration. A UNICEF: New York, NY. Practices: old beyond imaginings. Addiss Abab.

Population Council. (2004). The experience of adolescence in rural Amhara Region: Ethiopia.

Population Council. (2010). Ethiopia gender survey. A study in seven regions, Population Council: Ethiopia and New York.

Proclamation, P. (2000). A proclamation by the president of the United States of America, William J. Clinton, Signed February 29th.

Save the Children. (2004). Adolescents, early marriage and the convention on the right of the Child; Stockholm Swedn.

Singh, S., \& Samara, R. (1996). Early marriage among women in developing countries. International Family Planning Perspectives, $148-175$.

Toubia, N. (1993). Female genital mutilation: A call for global action. New York: Women' Ink,s.

Umashankar, D. (2006). Women's empowerment: effect of participation in self-help groups. Bangalore: Indian Institute of Management.

UNFPA, A. (2006). Passage to hope, women and international migration. State of World Population.

UNICEF. (1997). The state of the world's children. New York: Oxford Uni. Pr.

UNICEF. (2001). Early marriage: Child spouses. Florence: International Research Center (IRC), Innocenti Digest, No. 7.

UNICEF. (2004). Fighting early marriage to increase girls' education. Retrieved from www.unicef.org/ethiopia/ET_Bugna.pdf.

UNICEF. (2005). Early marriage: A harmful traditional practice.

United Nations Educational, S. C. O. U. (2002a). Early marriage and early childbearing: Old for toys, too young for marriage and childbearing.Retrieved from http://www.unesco.org/education/www.air-dc.org/pubs/PD8.pdf.

United Nations Population Fund (UNFPA) \& Engender Health. (2003). Obstetric Fistula needs assessment report: Findings from nine African countries. UNFPA and Engender Health: New York, NY.

USAID. (2008). Examining school related gender based violence; Washington DC.

WHO. (2000a). Violence against women. Fact sheet No.239 Geneva: World Health Organization.

WHO. (2000b). Human rights, women and HIV/AIDS. Fact sheet No. 247. Geneva: World Organization.

World Fertility Survey \& DHS. (2008). Age specific fertility rate for 224 countries or areas of the World, ORC Macro Calverton, Maryland. 